\title{
A new therocephalian (Gorynychus masyutinae gen. et sp. nov.) from the Permian Kotelnich locality, Kirov Region, Russia
}

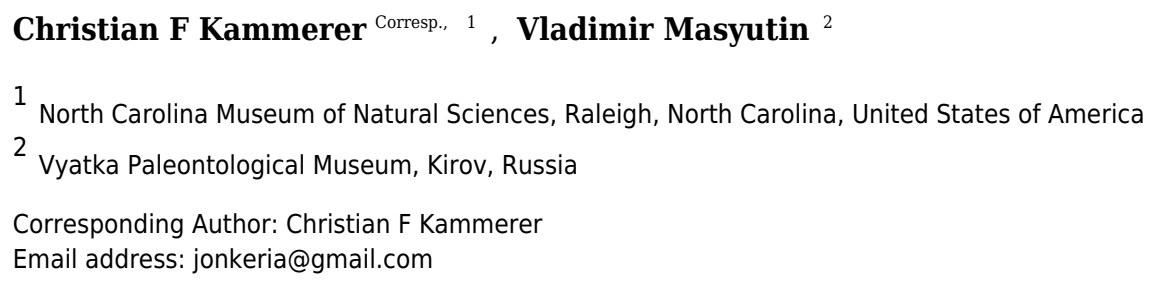

A new therocephalian taxon (Gorynychus masyutinae gen. et sp. nov.) is described based on a nearly complete skull and partial postcranium from the Permian Kotelnich locality of Russia. Gorynychus displays an unusual mixture of primitive ("pristerosaurian") and derived (eutherocephalian) characters. Primitive features of Gorynychus include extensive dentition on the palatal boss and transverse process of the pterygoid, paired vomers, and a prominent dentary angle; derived features include the absence of the postfrontal. Gorynychus can be distinguished from all other therocephalians by its autapomorphic dental morphology, with roughly denticulated incisors and postcanines. Phylogenetic analysis recovers Gorynychus as a non-lycosuchid, non-scylacosaurid therocephalian situated as sister-taxon to Eutherocephalia. The identification of Gorynychus as the largest predator from Kotelnich indicates that therocephalians acted as apex predators in middlelate Permian transition ecosystems in Russia, corroborating a pattern observed in South African faunas. However, other aspects of the Kotelnich fauna, and Permian Russian tetrapod faunas in general, differ markedly from those of South Africa and suggest that Karoo faunas are not necessarily representative of global patterns. 
1 A new therocephalian (Gorynychus masyutinae gen. et sp. nov.) from the Permian

2 Kotelnich locality, Kirov Region, Russia

3

4 Christian F. Kammerer ${ }^{1}$ and Vladimir V. Masyutin ${ }^{2}$

$6 \quad{ }^{1}$ North Carolina Museum of Natural Sciences, 11 W. Jones Street, Raleigh, North Carolina, USA

$7 \quad$ 2Vyatka Paleontological Museum, Spasskaya ulitsa 22, Kirov, Russia 610000

9 Correspondence to: C. F. Kammerer (christian.kammerer@naturalsciences.org)

11 Abstract. A new therocephalian taxon (Gorynychus masyutinae gen. et sp. nov.) is described

12 based on a nearly complete skull and partial postcranium from the Permian Kotelnich locality of

13 Russia. Gorynychus displays an unusual mixture of primitive ("pristerosaurian”) and derived

14 (eutherocephalian) characters. Primitive features of Gorynychus include extensive dentition on

15 the palatal boss and transverse process of the pterygoid, paired vomers, and a prominent

16 dentary angle; derived features include the absence of the postfrontal. Gorynychus can be

17 distinguished from all other therocephalians by its autapomorphic dental morphology, with

18 roughly denticulated incisors and postcanines. Phylogenetic analysis recovers Gorynychus as a

19 non-lycosuchid, non-scylacosaurid therocephalian situated as sister-taxon to Eutherocephalia.

20 The identification of Gorynychus as the largest predator from Kotelnich indicates that

21 therocephalians acted as apex predators in middle-late Permian transition ecosystems in

22 Russia, corroborating a pattern observed in South African faunas. However, other aspects of

23 the Kotelnich fauna, and Permian Russian tetrapod faunas in general, differ markedly from

24 those of South Africa and suggest that Karoo faunas are not necessarily representative of global 25 patterns. 


\section{INTRODUCTION}

27 Therocephalians had perhaps the most unusual evolutionary trajectory of the major clades of

28 non-mammalian therapsids. Whereas other non-mammalian therapsid groups remained

29 relatively static in terms of niche occupation through time, therocephalians 'reinvented'

30 themselves several times in their history, each time following mass extinctions. The earliest

31 known therocephalians (Lycosuchidae and Scylacosauridae, historically united in the

32 paraphyletic group "Pristerosauria" [Boonstra, 1953]), which are best represented in middle

33 Permian sediments of the Karoo Basin of South Africa, were large-bodied (skull length up to 40

$34 \mathrm{~cm}$ ) predators (Boonstra, 1969; van den Heever, 1980, 1994). Following the extinction of

35 dinocephalians (including the gigantic, carnivorous anteosaurs) at the end of the Capitanian,

36 therocephalians briefly served as the apex predators of the Karoo during the middle-late

37 Permian transition represented by the Pristerognathus Assemblage Zone (AZ) (Kammerer,

38 2011; Abdala et al., 2014; Day et al., 2015). However, by the end of the Pristerognathus AZ

39 lycosuchids and scylacosaurids were extinct, and the saber-toothed gorgonopsians had taken

40 over as the dominant large-bodied therapsid predators (Smith et al., 2012; Kammerer et al.,

41 2015). The surviving late Permian therocephalians all belong to the subclade Eutherocephalia,

42 which were predominantly small-bodied animals (skull length $\leq 10 \mathrm{~cm}$ ), many of which were

43 likely insectivores (Mendrez, 1975; Kemp, 1986; Huttenlocker, 2009). A few eutherocephalians

44 re-evolved large size and inferred macropredatory habits by the end of the Permian (e.g., the

45 whaitsiid Theriognathus and the akidnognathid Moschorhinus), but these taxa died out as a

46 result of the end-Permian mass extinction (Moschorhinus survived the main extinction pulse, but

47 disappears from the record shortly thereafter, making it an example of a 'dead clade walking';

48 Jablonski, 2002; Huttenlocker \& Botha-Brink, 2013; Huttenlocker, 2014). Remarkably, despite

49 major losses in the end-Permian mass extinction, therocephalians managed to reinvent

50 themselves yet again, with a moderately successful third act as small-bodied herbivores (the 
51 Bauriamorpha) in the Early-Middle Triassic (Sigogneau-Russell \& Sun, 1981; Abdala et al., 52 2014) before the clade was finally lost for good.

Basal therocephalians (lycosuchids and scylacosaurids) are the most common tetrapod

54 predators in middle and earliest late Permian deposits in South Africa, with hundreds of known specimens (Smith et al., 2012) and 55 named species (although this number is clearly oversplit; van den Heever, 1987). By contrast, very few basal therocephalian fossils have been found in comparably-aged Laurasian rocks, despite extensive records of anomodonts, dinocephalians, and parareptiles from the middle Permian of China and Russia (Li, 2001; Ivakhnenko, 2003). No therocephalians have ever been found in middle Permian Chinese rocks. Historically, only a single species of therocephalian (Porosteognathus efremovi, a possible scylacosaurid from the Isheevo locality, Apastovskii District, Tatarstan) was known from the middle Permian of Russia (Vjuschkov 1955; Ivakhnenko 2011). Furthermore, Porosteognathus seems to be a minor component of the Isheevo assemblage, which is dominated by dinocephalians and venyukovioid anomodonts (many known from complete skulls and skeletons, whereas Porosteognathus is known only from isolated skull bones).

The earliest Russian assemblage preserving a substantial number of therocephalians is the Kotelnich locality in Kirov Region. Although known since the 1930s as a source of spectacularly-complete pareiasaurs (Hartmann-Weinberg, 1937), therocephalians were not described from Kotelnich until the 1990s (Tatarinov, 1995a, 1995b, 1997, 1999a, 1999b). Now, however, they are the most species-rich tetrapod clade known from the site, with eight named species (Chlynovia serridentatus, Karenites ornamentatus, Kotelcephalon viatkensis, Muchia microdenta, Perplexisaurus foveatus, Scalopodon tenuisfrons, Scalopodontes kotelnichi, and Viatkosuchus sumini), although these may be somewhat oversplit (Ivakhnenko, 2011). The age of the Kotelnich assemblage is somewhat uncertain, with both middle and late Permian ages having been proposed (Tatarinov, 2000; Benton et al., 2012). Currently, an early late Permian age is considered most likely, possibly equivalent with the South African Tropidostoma AZ 
77 based on anomodont comparisons (Kurkin, 2011). Benton et al. (2012) instead suggested equivalency between the Kotelnich assemblage and the Pristerognathus AZ. However, the described therocephalian fauna of Kotelnich is composed entirely of eutherocephalians (which other than Viatkosuchus are very small, i.e., $<10 \mathrm{~cm}$ skull length), not the large scylacosaurids

81 or lycosuchids characteristic of the Pristerognathus AZ in South Africa. Here we describe a new taxon representing the first large, basal (i.e., noneutherocephalian) therocephalian from the Kotelnich locality. This species is represented by two specimens and is the largest known predatory therapsid from Kotelnich, indicating therocephalian occupation of apex predator niches in the Northern as well as Southern Hemisphere during the transition between middle and late Permian tetrapod faunas.

\section{Nomenclatural acts}

89 The electronic version of this article in portable document format (PDF) will represent a 90 published work according to the International Commission on Zoological Nomenclature (ICZN), 91 and hence the new names contained in the electronic version are effectively published under 92 that Code from the electronic edition alone. This published work and the nomenclatural acts it contains have been registered in ZooBank, the online registration system for the ICZN. The ZooBank LSIDs (Life Science Identifiers) can be resolved and the associated information viewed through any standard web browser by appending the LSID to the prefix http://zoobank.org/. The LSID for this publication is: urn:Isid:zoobank.org:pub:CA4D73A1-8FA740DD-A464-621AC01421B6. The online version of this work is archived and available from the 98 following digital repositories: PeerJ, PubMed Central, and CLOCKSS.

\section{Institutional abbreviation}

101 KPM, Vyatka Paleontological Museum, Kirov, Russia. 


\section{GEOLOGICAL CONTEXT}

104 The Kotelnich locality is a rich, tetrapod-bearing fossil assemblage in the Kirov Region of

105 European Russia. The first fossils found at this locality were two pareiasaur skeletons collected

106 by the hydrogeologist S. G. Kashtanov in 1933 (Kashtanov, 1934). Subsequent expeditions by

107 A. P. Hartmann-Weinberg (in 1935) and Kashtanov (in 1936) recovered additional pareiasaur

108 material (today all considered referable to Deltavjatia rossica; Benton et al., 2012; Tsuji, 2013).

109 Further expeditions by staff of the Paleontological Institute in Moscow occurred between the

110 1940s-1960s, collecting mostly Deltavjatia specimens (see, e.g., Efremov \& Vjuschkov, 1955).

111 Fossil collection at Kotelnich was renewed in the 1990s and has continued to the present day,

112 most recently through the efforts of the Vyatka Paleontological Museum in Kirov. These more

113 recent (1990s-present) excavations have revealed a substantially more diverse fauna than was

114 previously known, adding an array of anomodont, gorgonopsian, and therocephalian therapsids

115 as well as non-pareiasaurian parareptiles to the list of Kotelnich tetrapods (although Deltavjatia

116 remains the numerically dominant taxon; Benton et al., 2012).

117 Several fossiliferous layers are present at Kotelnich; the lowest red beds represent a

118 lacustrine or floodplain system which famously preserves numerous complete, fully articulated

119 skeletons of the mid-sized pareiasaur Deltavjatia rossica. This level (the Vanyushonki Member

120 of Coffa [1999]) has also produced the majority of synapsid finds, including spectacular

121 examples such as the complete, articulated specimen of the small gorgonopsian Viatkogorgon

122 ivakhnenkoi (Tatarinov, 1999a) and a block containing 15 skeletons of the arboreal anomodont

123 Suminia getmanovi (Fröbisch and Reisz, 2011). Although most Kotelnich tetrapods are found in

124 the red-brown mudstones at the base of the succession, plants, fish, and highly fragmentary

125 tetrapod remains (primarily isolated teeth) are also present in lenses of later deposition at the

126 top of the section (Benton et al., 2012).

127 The specimens of the new therocephalian described herein were all found in the lower

128 red beds (Vanyushonki Member). The holotype was discovered in 2008 by I. Shumov, 10.15 
129 meters below the marker bed and 413 meters upstream from the village of Nizhnaya Vodskaya.

130 These specimens were mechanically prepared by O. Masyutina and are housed in the

131 collections of the Vyatka Paleontological Museum in Kirov.

132

133 SYSTEMATIC PALEONTOLOGY

134 Synapsida Osborn, 1903

135 Therapsida Broom, 1905

136 Therocephalia Broom, 1903

137

138 Gorynychus gen. nov.

139

LSID: urn:Isid:zoobank.org:act:CD10EB7C-57C0-45BA-8467-75309411E0DD Type species: Gorynychus masyutinae sp. nov. Etymology: Named for the legendary Russian dragon Zmey Gorynych (Змей

143 Горыныч), in reference to the fearsome appearance of this taxon and its status as the largest

144 known predator in the Kotelnich assemblage. Also a play on the English word 'gory' (meaning

145 bloody) and the Ancient Greek övŭxoৎ (Latinized 'onychus', meaning claw), in reference to this 146 taxon's inferred behavior being 'red in tooth and claw.'

147 Diagnosis: As for type and only species.

149 Gorynychus masyutinae sp. nov.

150 (Figs. 1-11)

LSID: urn:Isid:zoobank.org:act:105CB020-2584-4AD1-BF98-2B555EE69644

Holotype: KPM 346-349 (Figs. 1-9), a single individual (skull and cervical vertebrae in

154 articulation, pectoral and rib elements disarticulated but directly associated with skull) broken 
155 into four pieces: KPM 346, a nearly complete skull (with damaged intertemporal region, occiput,

156 and left temporal arcade) and lower jaws with the anterior 4 1/2 cervicals in articulation; KPM

157347 , postcranial elements including remaining half of fifth cervical (precise break, originally

158 articulated with anterior portion) and worn sixth and seventh cervicals, ribs, partial clavicle, and

159 left scapulocoracoid impression; KPM 348, isolated but associated incisor with intact crown; and

160 KPM 349, isolated but associated incisor with damaged crown.

161 Referred material: KPM 291 (Figs. 10, 11A-C), a block of fragmentary, disarticulated

162 elements including the anterior portion of a partial right dentary, an isolated incisor, a jugal, at

163 least four vertebrae, several ribs, a fibula, and various indeterminate bone fragments. KPM

164 448/1 (Fig. 11D), an isolated incisor with damaged root.

165 Etymology: Named in honor of Olga Masyutina for her skillful preparation of the

166 holotype of this taxon, as well as numerous other important specimens from the Kotelnich

167 locality.

168 Diagnosis: Therocephalian distinguished from all other members of the group by its

169 autapomorphic dental morphology: all marginal teeth serrated, with serrations forming distinct

170 denticles that are especially prominent on the incisors and postcanines. Postcanines 'spade'-

171 shaped and reduced in number (three in the maxilla) relative to most therocephalians. Further

172 distinguished from the other known Russian basal therocephalian Porosteognathus efremovi by

173 a shorter tooth row on the pterygoid transverse process situated on a more discrete, raised boss

174 and an anterolaterally-curved and expanded pterygoid palatal boss with fewer (8-9) teeth

175 (transversely broad with $\sim 14$ teeth in Porosteognathus).

176

\section{DESCRIPTION}

178 The holotype is generally well preserved (Fig. 1), with good bone quality showing surface

179 ornamentation and sutural boundaries on most of the snout and palate (Figs. 2-7). However,

180 the skull is somewhat crushed, the left temporal arch is broken off, and the intertemporal region 
181 is badly eroded. The anterior five cervicals are reasonably well preserved (although the atlas is

182 not exposed as prepared), but the subsequent members of the series are badly worn (Fig. 8).

183 Other postcranial elements are broken and worn, and the scapulocoracoid is preserved mainly

184 as an impression (Fig. 9). The more extensive of the two referred specimens is a single block of

185 disarticulated, fragmentary elements (Fig. 10), although most of these elements show good

186 bone preservation (Fig. 11A-C). One of these elements, an isolated incisor with intact crown,

187 can confidently be referred to Gorynychus masyutinae based on the presence of very large,

188 curved denticles on its mediodistal edges. The dentary fragment also has a tall, robust

189 symphysis identical to that of the holotype; although it is possible this could represent a

190 gorgonopsian, the only gorgonopsians known from this locality are much smaller and actually

191 have weakly-developed dentary symphyses. Given the absence of any other material that is not

192 consistent with identification as Gorynychus and the lack of overlapping elements, this set of

193 fossils is interpreted to be the remains of a single Gorynychus individual. An additional isolated

194 tooth (KPM 448/1; Fig. 11D) exhibits the same denticulation and general morphology as those

195 of KPM 348 and KPM 291 (Figs. 2C, 11C) and can also be referred to Gorynychus masyutinae.

197 Cranium

198 The cranium of KPM 346 is $173 \mathrm{~mm}$ in standard basal length (from anteroventral edge of

199 premaxilla to posteroventral edge of occipital condyle) and $208 \mathrm{~mm}$ in total dorsal length (from

200 tip of snout to edge of temporal fenestra).

201 The palatal portion of the premaxilla is not exposed in the holotype because of occlusion 202 of the lower jaw. The only information available concerning the ventral surface of the premaxilla 203 comes from the edges of the incisor alveoli. Based on this, Gorynychus appears to have had an 204 upper incisor count of five. Although no incisors are preserved in place, two isolated teeth (KPM 205348 and 349) preserved in association with the skull have root proportions identical to the empty 206 alveoli and are here interpreted as the upper incisors. Only one of these teeth (KPM 348) 
207 preserves an intact crown (Fig. 2C). The crown of KPM 348 is elongate, triangular, and weakly

208 recurved with prominent mesiodistal serrations forming distinct denticles. The morphology of

209 these denticles is unique among therocephalians: they are extremely prominent, extend from

210 the tip of the crown right to the root, and each individual denticle is curved in the apical direction.

211 This only comparable morphology among therocephalians occurs in the postcanines of this

212 same specimen. The cutting edges of KPM 348 are heavily worn, but this wear is asymmetrical.

213 As shown in Figure 2C, one side of the tooth (it is uncertain whether this is the mesial or distal

214 side) has more of its margin worn down than the other. The same style of asymmetrical wear,

215 but with the sides reversed, is present on KPM 448/1 (Fig. 11D). The isolated incisor of KPM

216291 , by contrast, is relatively unworn (Fig. 11C). It is uncertain whether this is simply due to

217 recent eruption before the death of the animal or from occupying a different position in the tooth

218 row (its crown is shorter and slightly more curved than in KPM 348 or KPM 448/1, which could

219 be because it represents a more posterior tooth position or a lower incisor).

220 The facial surface of the premaxilla is overlain by the maxilla posteriorly, near the point

221 between the alveoli for 14 and I5 (Figs. 2, 4, 5). The bone surface of the premaxilla is rugose,

222 with a series of well-developed foramina located 3-4 mm above the alveolar margin. Anteriorly,

223 three foramina are situated in a distinct channel that originates vertically beneath the internarial

224 bar then curves posterolaterally (Fig. 2B). The first and third foramina in this channel are small

225 (<1 $\mathrm{mm}$ diameter), but the second is large (1 $\mathrm{mm}$ diameter) and situated deep inside the

226 groove. Posterior to this channel, several additional foramina are present on the lateral face of

227 the premaxilla. The internarial bar is angled somewhat anteriorly, such that it overhangs the

228 alveolar portion of the premaxilla in lateral view (Fig. 4). The ascending ramus of the premaxilla

229 frames the anterodorsal border of the external naris and terminates near the posterodorsal

230 narial border.

231 The septomaxilla consists of a broad ventral plate making up the base of the external

232 naris, a constricted intranarial portion, and a facial process extending between the maxilla and 
233 nasal (Figs. 2, 4, 5). The ventral plate of the septomaxilla is situated immediately dorsal to the

234 premaxillary-maxillary suture. Immediately ventral to this plate is a large, ovoid foramen $(1.5 \mathrm{~mm}$

235 diameter) that spans the premaxillary-maxillary suture. A weak groove extends anterior to this

236 foramen for the length of the ventral plate of the septomaxilla. The constricted intranarial portion

237 of the septomaxilla separates the main portion of the external naris from the maxillo-

238 septomaxillary foramen. It has a pointed, anteromedially-directed anterior process as is typical

239 of therocephalians, but not an expanded transverse lamina as in gorgonopsians.

240 Posterodorsally, the septomaxilla makes a broad, irregular contribution to the facial portion of

241 the snout. This facial process notably does not make up the entire posterior margin of the

242 external naris-the nasal occupies the posterodorsal narial corner (Fig. 2B).

243 The maxilla is a tall, gently curved bone making up the main lateral surface of the snout

244 (Figs. 4, 5). The facial surface of the maxilla is intensely sculptured with shallow, crater-like

245 structures and small foramina, similar to that of some other basal therocephalians (see, e.g.,

246 Abdala et al., 2008). A labial emargination is absent, unlike in Lycosuchus. The posterior

247 terminus of the maxilla is a process under the jugal that reaches the midpoint of the orbit. The

248 tip of this process is notably expanded and rugose, but the majority of this process is notable for

249 lacking the dermal sculpturing so prominent on the rest of the maxilla and bearing a weak lateral

250 groove. The maxilla houses four teeth: the enlarged, blade-like canine and three small

251 postcanines. The canine is recurved and has well-developed serrations fore and aft, as is usual

252 in basal therocephalians (van den Heever, 1994; Abdala et al., 2014). Only a single canine is

253 erupted on each side; unlike the usual condition in lycosuchids and a frequent condition in

254 scylacosaurids, there are not simultaneously-occupied anterior and posterior canine alveoli. The

255 tip of a replacement canine is erupting anterior to the right canine, however. The postcanine

256 morphology of Gorynychus is unique among therocephalians - these teeth are labiolingually

257 compressed and 'leaf' or 'spade'-shaped, with proportionally large denticles (serrations) along

258 both mesial and distal edges (Fig. 6). Although these denticles are not as large or exaggeratedly 
259

260

261

262

263

264

265

266

267

268

269

270

271

272

273

274

275

276

277

278

279

280

281

282

283

284

curved as those on the incisors, they still show distinct curvature (unlike the finer, straight serrations on the canine). As for the premaxilla, the palatal surface of the maxilla is for the most part not visible in this specimen.

The nasal is a long, flat bone (Figs. 2-5). It also bears dermal sculpturing, albeit developed to a lesser degree than in the facial portion of the maxilla. Dermal sculpturing to some degree is present on all the bones of the snout, including (albeit very weakly) on the facial portion of the jugal. The naso-frontal suture is slightly bowed posteriorly and terminates near the anterior margin of the orbit.

The prefrontal is a roughly trapezoidal bone making up part of the snout and the anterodorsal margin of the orbit (Figs. 3-5). Its contribution to the orbital rim is unusually pronounced and rugose. This is also true for the lacrimal, jugal, and frontal, such that that the circumorbital rim is very prominent everywhere but on the postorbital bar. Anteriorly, the prefrontal terminates in a short process extending between the maxilla and nasal. The prefrontal makes up a large portion (roughly half) of the anterior face of the orbital wall, and appears to exclude the frontal from contacting the lacrimal.

The lacrimal is a large facial bone, nearly equivalent in height to the prefrontal albeit not as anteroposteriorly long (Figs. 4, 5). A similarly-sized lacrimal is also present in Lycosuchus, and although this bone is less dorsoventrally expanded in scylacosaurids it is of similar anteroposterior dimensions in that group as well (van den Heever, 1994). A large (1.5 mm diameter) lacrimal foramen is present on its contribution to the anterior orbital wall; this foramen does not exit onto the lateral surface. A second, smaller lacrimal foramen may be present ventral to the first, but this is uncertain because of damage.

The jugal makes up the majority of the zygomatic arch (Fig. 4). Its facial portion is an attenuate process terminating below the lacrimal, posterior to the anterior lacrimal margin. This facial portion is remarkably small for an early theriodont. In gorgonopsians, the jugal typically terminates in a broad, plate-like contribution to the snout equalling (or exceeding) the lacrimal in 
285

286

287

288

289

290

291

292

293

294

295

296

297

298

299

300

301

302

303

304

305

306

307

308

309

anterior extent (see, e.g., Kammerer, 2015; Kammerer et al., 2015). In Lycosuchus and other early therocephalians, the facial portion of the jugal terminates well posterior to the anterior edge of the lacrimal, but still forms a tall plate on the snout and occupies almost the entire ventral margin of the orbit (van den Heever, 1994). The jugal is constricted beneath the posterior margin of the orbit, before expanding to form a major part of the postorbital bar. In the postorbital bar, an ascending process of the jugal extends dorsally behind the postorbital.

Posterior to the postorbital bar the jugal makes a tall contribution to the subtemporal bar, narrowing posteriorly and curving downwards. In the posterior half of the subtemporal bar, the jugal is bifurcated by an anterior process of the squamosal. The ventral portion of the jugal extends nearly to the back of the skull, and has a weakly bulbous terminus. In addition to being preserved in the holotype, an isolated jugal is present on the referred block (Fig. 10), identifiable by the characteristic subtemporal curvature and well-developed process contributing to the postorbital bar.

The squamosal is preserved mainly in its zygomatic ramus (Fig. 4), as the occiput and intertemporal region are poorly preserved in this specimen (Fig. 1). It has a deep and fairly restricted squamosal sulcus, giving it a 'forked' appearance in lateral view. Medially, it forms the posterior portion of the lateral margin of the temporal fenestra (anteriorly, this margin is formed by the jugal).

The frontal is a mostly-flat bone making up the interorbital skull roof (Fig. 3). The medial portion of the frontal is damaged in this specimen, but its contribution to the orbit is well preserved and shows that it was only weakly ornamented dorsally, until the very edge of the orbit (in which it is expanded and rugose, like most of the circumorbital rim). The suture between the frontal and postorbital is poorly preserved and difficult to interpret, but it appears that the frontal makes only a narrow contribution to the dorsal orbital wall (Fig. 4), as in Lycosuchus (van den Heever, 1994). 
A distinct postfrontal is absent in Gorynychus; this element may be fused with the

311 postorbital. The postorbital makes up a broad portion of the skull roof at the posterodorsal

312 margin of the orbit and continues as a posterior ramus making up the medial face of the

313 temporal fenestra (Figs. 3, 4). The latter ramus is badly damaged in this specimen, like most of

314 the posterior skull roof, and its posterior terminus and surface texture is indeterminable. The

315 intertemporal bar is narrow, as its typical of therocephalians. However, this region is too

316 damaged to determine its exact proportions or presence/absence of the pineal foramen or

317 sagittal crest. The occiput is even more badly damaged, being worn off entirely dorsal to the

318 occipital condyle (Fig. 5).

319 The vomer is not exposed anteriorly, but its posterior interchoanal portion is a tall,

320 narrow blade, like that of scylacosaurids and unlike the broad, vaulted morphology of

321 Lycosuchus (Fig. 7). The vomer is paired-a distinct mid-vomerine suture is visible in the

322 interchoanal portion. Posteriorly, the vomer forms a broad, triangular contribution to the palate,

323 extending between the palatines to contact the anterior margin of the pterygoids posteriorly. An

324 elongate palatal depression or fossa is present medially, originating near the anterior edge of

325 the plate-like palatal portion of the vomer and extending posteriorly until it reaches the

326 transverse processes of the pterygoids. Although the depth of this structure is likely

327 exaggerated by lateral compression in this specimen, its presence is natural.

328 The palatine is the largest bone of the palate (Fig. 7). It is a topologically complex

329 element composed of a laminar anterior process that forms much of the lateral margin of the

330 choana and a broad main portion with a prominent central ridge bounded by medial and lateral

331 depressions. This central ridge extends anterolaterally to posteromedially and is confluent

332 posteriorly with a ridge on the pterygoid, terminating with the palatal boss. A suborbital fenestra,

333 characteristic of therocephalians, is present at its posterolateral margin, bounded posteriorly by

334 the pterygoid. Presumably it is also bounded laterally by the ectopterygoid, but this element is

335 indistinct if present, probably due to poor preservation of the lateral margins of the palate. 
As is typical of early therapsids, the pterygoid consists of three distinct processes:

337 palatal, transverse, and quadrate (Fig. 7). The palatal portion of the pterygoid has an

338 anteromedial-to-posteromedially-angled, strongly interdigitated suture with the palatine.

339 Anteriorly it forms a short portion of the prominent palatal ridges (central ridge of palatine)

340 before expanding into the dentigerous palatal bosses posteriorly. Dentigerous palatal bosses

341 are ancestral for therapsids; although they are present in scylacosaurids and even various

342 eutherocephalians (van den Heever, 1994; Huttenlocker \& Smith, 2017), they are absent in

343 lycosuchids (Lycosuchus and Simorhinella) (Abdala et al., 2014). The palatal boss is 'teardrop'-

344 shaped, with a narrow posterior tip and broad, rounded anterior. It is curved anterolaterally. The

345 boss bears two tooth rows. On the left palatal boss (the more completely preserved of the two),

346 the posterior tooth row follows the curve of the boss and is made up of five teeth. The anterior

347 tooth row is transversely oriented and is made up of four teeth, for a total of nine (six are

348 present on the right boss, but as mentioned this boss is damaged and this is probably not the

349 complete complement of teeth). The transverse process of the pterygoid extends ventrolaterally:

350 it has a broad base medially, constricts in ventral view towards its midpoint, and then expands

351 into a rounded lateral tip where it braces the mandible. The anterior face of the transverse

352 process bears a broad, shallow depression. Unlike most therocephalians, but similar to

353 lycosuchids, the transverse process is dentigerous in Gorynychus. Unlike Lycosuchus and

354 Simorhinella, however, where the tooth row is relatively long (five teeth) and the teeth erupt

355 directly from the main ramus of the transverse process, in Gorynychus there are only 2-3 teeth

356 situated on discrete, ovoid bosses raised above the medial bases of the transverse processes.

357 On the right transverse process there are only two teeth, a large lateral and small medial one;

358 on the left there are three teeth of equal size, similar to the small one on the right. No

359 interpterygoid vacuity is present; although there is a weak depression between the transverse

360 processes medially, it is entirely bounded by bone dorsally. The quadrate process of the

361 pterygoid is situated dorsal to the transverse process. It extends posterolaterally from a position 
362 near the medial base of the transverse process towards the quadrate, weakly curving along its

363 length. The anterolateral margin of the quadrate process forms a tall, narrow ridge;

364 posteromedially it forms a broad, concave plate bounding the lateral edge of the parasphenoid 365 rostrum.

366 The parasphenoid-basisphenoid complex forms a narrow median rostrum originating

367 behind the transverse processes of the pterygoids and extending posteriorly to the basal tubera

368 (Fig. 7). Although tall and blade-like posteriorly, the anterior two-thirds of this complex are

369 divided by a narrow median groove. The posterior terminus of the rostrum is abrupt, with a

370 sharp drop to the base of the basal tubera (typical of early therocephalians) instead of a gradual

371 decrease in height. Dorsally, the parasphenoid forms a narrow median lamina above the

372 pterygoid, forming part of the mid-orbital plate (Fig. 5). Dorsal to this anteriorly is a tall, laminar

373 bone interpreted as the orbitosphenoid, which extends dorsally to contact the frontal-postorbital

374 wall of the orbit. Dorsal to it posteriorly is the epipterygoid, which has an anteroposteriorly broad

375 footplate ventrally that sits atop the pterygoid. The ascending process of the epipterygoid

376 narrows dorsally before expanding again at its contact with the ventral face of the parietal. The

377 basal tubera are broadly separated by a median depression (Fig. 7). They are relatively slender

378 and angled medially at their posterior end. The left stapes is preserved in place, extending from

379 the basal tuber to near the quadrate. The stapes is dorsoventrally narrow but anteroposteriorly

380 broad, although narrowing along its length laterally (similar to Lycosuchus). No foramen or

381 dorsal process is visible, but these could be obscured by matrix. The basioccipital forms a plate

382 posterior to the basal tubera and terminates in the occipital condyle, which is similar to that of

383 other therocephalians.

384 The dentary is a massive, robust bone with a tall, well-developed, unfused symphysis

385 more similar to that of gorgonopsians than other early therocephalians (Figs. 2, 4, 5, 11A). The

386 anterior face of the symphysis is densely foraminated. The roots of at least three incisors are

387 exposed due to damage to the right dentary (Fig. 4), but it is probable that more were present, 
388 given that these three do not occupy the entirety of the symphysial length. The crowns of the

389 lower incisors are not exposed. The lower canine is not exposed in the holotype but is well-

390 preserved in the disarticulated dentary fragment in KPM 291 (Figs. 10, 11A). The lower canine

391 is a tall, recurved tooth with well-developed fore and aft serrations. It is proportionally large,

392 taking up much of the alveolar margin of the symphysis. Based on this position, it would have

393 been situated anterior to the upper canine when in occlusion with the cranium. The lower

394 postcanines are mostly obscured in both known specimens of Gorynychus, only a single small

395 lower postcanine is exposed on the right mandibular ramus anterior to the upper PC1 in the

396 holotype. This postcanine is smaller than any of the upper postcanines (2 $\mathrm{mm}$ apicobasal

397 length, versus $4 \mathrm{~mm}$ in the uppers) but is otherwise similar in morphology, being 'spade'-shaped

398 with well-developed denticulation. The dentary is constricted behind the symphysis, then

399 expands posteriorly, with a well-developed angular process (Fig. 4). The dorsal and ventral

400 margins have raised edges, and a distinct lateral fossa is present between them, extending

401 anteriorly almost to the level of the symphysis. Although superficially similar to the masseteric

402 fossa of cynodonts, this fossa is likely non-homologous; there is no evidence that the superficial

403 masseter was present in therocephalians. The raised ventral margin of the dentary terminates

404 posteriorly in a broad, flattened rugose region serving as the attachment site for adductor

405 musculature. The coronoid process extends freely above the postdentary bones and has a

406 broad posterodorsal terminus, as in the other basal therocephalians (van den Heever, 1994).

407 Unlike Lycosuchus, however, in which the posterior edge of the coronoid process is broadly

408 rounded, in Gorynychus this edge is nearly straight (slightly concave).

409 The postdentary bones are damaged on both sides of the skull: the surangular and

410 articular are more complete on the right side but the reflected lamina of the angular is broken off

411 ventrally; the surangular and posterior portion of the angular are broken off on the left side but

412 the reflected lamina is more complete (Figs. 4, 5). In general, the postdentary elements are very

413 similar to those of lycosuchids and scylacosaurids. The reflected lamina is large and occupies 
414 the entire lateral surface of the angular (typical of early therapsids, but distinct from

415 gorgonopsians in which it is usually widely separated from the articular). The surface structure

416 of the reflected lamina is typical of early therocephalians: an anterodorsal depression becoming

417 a single broad ridge posteroventrally that then ramifies into ventral and posterior ridges. The

418 surangular is exposed laterally as a narrow, curved element atop the angular, contacting the

419 articular posteroventrally. A short angle is present at the posterior base of the coronoid process

420 of the dentary where it overlies the surangular, and the dentary is weakly raised laterally anterior

421 to this point, accommodating the internal anterior process of the surangular. The splenial is a

422 tall, 'ribbon'-like bone occupying the medial face of the anterior portion of the jaw ramus (Fig. 7).

423 It lacks any lateral exposure, being restricted to the internal surface of the jaw. It covers almost

424 all of the medial surface of the dentary anteriorly, but decreased in height posteriorly before

425 terminating at the level of the transverse process of the pterygoid. Dorsal to the splenial is a

426 narrow, laminar bone: the prearticular. This element broadens posteriorly and becomes more

427 raised and rod-like posterior to the dentary, terminating in an indistinct contact with the articular.

428 Dorsal to the prearticular at roughly the mid-length of the jaw ramus is a short, narrow, laminar

429 element interpreted as being the coronoid. The articular is poorly preserved on both sides in this

430 specimen, but a bulbous, cup-like terminus articulating with the (equally poorly preserved)

431 quadrate can be discerned in medial view on the left side (Figs. 4, 7). Although mostly worn off,

432 the base of a large retroarticular process is present.

433

\section{Postcranium}

435 Little of the postcranium is preserved in the holotype of Gorynychus masyutinae. The majority of

436 the cervical series is preserved in articulation with the skull and some ribs and pectoral

437 elements are preserved posterior to this (Fig. 1). The atlas-axis complex is somewhat damaged

438 and obscured by the skull and surrounding matrix and C5-7 are broken and badly worn, but C3

439 and 4 are well-preserved and exposed on both sides (Fig. 8). The cervical vertebrae are 
440 amphicoelous (except, presumably, the atlas) and are separated ventrally by small, wedge-

441 shaped intercentra. The transverse processes are short and blunt. At least one cervical rib is

442 preserved on the right side of the specimen in association with (but disarticulated from) vertebra

443 C3. This rib has a broadly falcate head and mediolaterally narrow main body. Well-developed,

444 stout prezygapophyses (12 $\mathrm{mm}$ anteroposterior length) extending anterior to the centra are

445 present in C3 and 4, contacting the associated postzygaphophyses of the anterior vertebrae

446 ventrally (and slightly laterally, as the prezygapophysis bulges out somewhat at its anterodorsal

447 edge). No anapophyses are present. The neural spines of C3 (17 mm tall) and 4 are constricted

448 immediately above their point of origin but expand dorsally into broad, rounded tips

449 (anteroposteriorly $11 \mathrm{~mm}$ long in C3). The axial neural spine is definitely anteroposteriorly

450 broader than that of the subsequent vertebrae (Fig. 8), but its exact dimensions (including

451 height relative to subsequent neural spines) are uncertain due to crushing. An isolated vertebra

452 interpreted as the axis in the referred specimen KPM 291 preserves a tall, broad neural spine

453 (Fig. 10), suggesting that the axial spine was substantially taller and longer than subsequent

454 neural spines, as is typical for theriodonts (Jenkins, 1971). The other vertebrae preserved in

455 KPM 291 have relatively lower, longer centra and shorter neural spines (Fig. 11B) than those of

456 C3 and 4 in the holotype. They likely represent dorsals or even anterior caudals, although most

457 are too poorly preserved to identify with any confidence.

458 The non-vertebral postcranial elements in the holotype are mostly damaged (Fig. 9) The

459 remains of at least eight ribs are present, but little of their morphology is exposed other than

460 simple, curved shafts. A robust, curved elongate bone exposed in worn cross-section probably

461 represents the clavicle, but nothing more about its morphology can be said. The left

462 scapulocoracoid is preserved almost entirely as impression (there is a small chunk of actual

463 bone from the anterior margin of the procoracoid). This impression shows that the coracoid-

464 procoracoid base of the structure was very anteroposteriorly long. The scapula is broad

465 ventrally but narrows markedly dorsally, where it curves anteriorly at tip. A prominent ridge on 
466 the scapula originates at the posterior margin of this element before curving anteriorly along the

467 length of the scapular spine. An elongate bone preserved as part of KPM 291 (Fig. 10) is here

468 identified as a fibula. This element lacks the curvature seen in the cervical-thoracic ribs on this

469 block and in KPM 347, and is too long to be a lumbar rib. Additionally, it is expanded at both

470 ends, unlike a rib. The morphology of this element is similar to the fibula of other

471 therocephalians, in which it is usually a narrow, simple bone (Fourie \& Rubidge, 2009).

472

473 PHYLOGENETIC ANALYSIS

474 Gorynychus masyutinae was coded into a recent analysis of therocephalian interrelationships,

475 that of Huttenlocker \& Smith (2017). This analysis (available as Supplemental Information)

476 includes 136 discrete-state characters and 58 taxa, including two newly added to the analysis:

477 Gorynychus masyutinae, coded based on personal examination of all known specimens, and

478 Shiguaignathus wangi, coded based on the figures in Liu \& Abdala (2017). Analysis was

479 undertaken using heuristic searching in PAUP* (Swofford, 2002) v.4.0a (build 159), treating

480 Biarmosuchus tener as the outgroup. All characters were treated as unordered following

481 Huttenlocker \& Smith (2017). Bootstrap analysis was done using "fast" stepwise addition for

4821000 replicates.

4831260 most parsimonious trees of length 383 were recovered (consistency index $=0.420$,

484 retention index $=0.785)$. The strict consensus tree recovers Gorynychus masyutinae as the

485 sister-taxon of Eutherocephalia (i.e., Akidnognathidae+Whaitsioidea+Baurioidea) (Fig. 12). A

486 position outside of Eutherocephalia is supported by the presence of a paired vomer, serrations

487 on all marginal teeth, and teeth on the transverse process of the pterygoid in Gorynychus (all of

488 which are typically absent in eutherocephalians) and the absence of a well-developed

489 mandibular fenestra penetrating the jaw in lateral view. The absence of the postfrontal in

490 Gorynychus is a character shared with eutherocephalians to the exclusion of lycosuchids and

491 scylacosaurids (although this element is still variably present in some hofmeyriids). The addition 
492 of Gorynychus adds substantial instability to the analysis of Huttenlocker \& Smith (2017),

493 notably with the complete collapse of Whaitsioidea (although a core Hofmeyriidae composed of

494 Hofmeyria, Ictidostoma, and Mirotenthes is retained). Another Kotelnich taxon, Perplexisaurus,

495 also falls outside of Eutherocephalia in the current analysis, occupying the node between

496 Scylacosauridae and (Gorynychus+Eutherocephalia). In previous analyses, Perplexisaurus was

497 a highly unstable taxon generally occupying a position somewhere near the base of

498 Eutherocephalia (Huttenlocker \& Sidor, 2016; Huttenlocker \& Smith, 2017), so its continued 499 lability is not especially surprising.

$500 \quad$ The breakdown of one of the major eutherocephalian clades (Whaitsioidea) as the sole

501 result of adding Gorynychus to the dataset indicates remarkably poor support for a group that,

502 on a strictly gestalt basis, seems to be very well-characterized. This problem can likely be

503 blamed on extensive homoplasy in Eutherocephalia, the mosaic of features present in

504 Gorynychus, as well as the need for additional sources of phylogenetic data. Existing

505 phylogenetic data sets for Therocephalia are heavily skewed towards craniodental characters;

506 for example, only 19/136 characters in Huttenlocker \& Smith's (2017) analysis are postcranial.

507 Although cranial-focused analyses are typical for Therapsida (an artifact, in part, of preferential

508 collection of skulls by Karoo paleontologists during most of the 20th century), recent analyses of

509 synapsid relationships (e.g., Benson, 2012) have highlighted the importance of bringing more

510 robust sets of postcranial data to bear on phylogenetic problems in this clade. Before such data

511 can be incorporated into therocephalian analyses, however, more basic descriptive work on

512 therocephalian postcrania is needed. Although skeletons are now known for a wide array of

513 taxa, anatomical descriptions are currently available for only a select few (e.g., Kemp, 1986;

514 Fourie \& Rubidge, 2009; Botha-Brink \& Modesto, 2011; Fourie, 2013).

515

516 DISCUSSION 
517 At roughly $20 \mathrm{~cm}$ in skull length, Gorynychus is the largest predatory component of the

518 Kotelnich tetrapod assemblage. Co-occurring gorgonopsians are substantially smaller, with skull

519 lengths less than $10 \mathrm{~cm}$. The only other Kotelnich predators approaching Gorynychus in size

520 are the eutherocephalian Viatkosuchus (co-occurring with Gorynychus in the Vanyushonki

521 Member) and the burnetiamorph Proburnetia (known only from the holotypic mould from the

522 younger Sokol'ya Gora site) (Ivakhnenko, 2011; Benton et al., 2012). This situations parallels

523 that of middle-earliest late Permian faunas in South Africa (the Tapinocephalus and

524 Pristerognathus AZs), wherein the only gorgonopsians are small animals and therocephalians

525 are the larger-bodied predators (Kammerer, 2014). The Kotelnich predatory fauna is particularly

526 comparable to that of the Pristerognathus AZ; in the middle Permian Tapinocephalus AZ,

527 although large-bodied therocephalians were abundant, the apex predators were gigantic

528 anteosaurian dinocephalians. The extinction of anteosaurs at the end of the Capitanian left a

529 depauperate fauna with therocephalians momentarily atop the food chain (Day et al., 2015). It

530 was only following the later extinction of these basal therocephalians that gorgonopsians began

531 to diversify and cemented their position as the dominant large-bodied therapsid predators

532 (Kammerer et al., 2015).

533 Although the presence of a therocephalian apex predator and relatively small

534 gorgonopsians in Kotelnich indicates that the earliest South African records may accurately

535 reflect ancestral body size in these clades (rather than regional peculiarities), in other regards

536 the Kotelnich fauna differs markedly from that of the Karoo. The dominant herbivorous taxon in

537 the Kotelnich fauna, and most abundant tetrapod of any kind, is the pareiasaur Deltavjatia

538 (Tsuji, 2013). This pattern is in stark contrast to that of South Africa, where dicynodont

539 therapsids are numerically dominant in all middle-late Permian faunas (Smith et al., 2012).

540 Furthermore, this does not seem to be an isolated oddity, as the best-sampled later Permian

541 Russian tetrapod fauna (North Dvina, a.k.a. Sokolki) also has pareiasaurs (Scutosaurus) as the 
542 dominant component (although there the top predator is the giant gorgonopsian Inostrancevia;

543 this inferred predator-prey pair represents the 'oligobiomorph community' of Ivakhnenko [2008]).

544 The therocephalian fauna in Kotelnich is also unusual even by comparison to the

545 Pristerognathus AZ. Although eutherocephalian fossils have been found in the Pristerognathus

546 AZ, they are rarer than scylacosaurids/lycosuchids and are relatively poorly known

547 (Huttenlocker \& Smith, 2017). By contrast, eutherocephalians are the most abundant and

548 species-rich theriodonts at Kotelnich. As such, the Kotelnich fauna seems to capture a phase in

549 therocephalian evolution not well-represented in the South African record: the initial

550 diversification of Eutherocephalia. The recovery of Gorynychus as a taxon just outside of

551 Eutherocephalia, rather than a lycosuchid or scylacosaurid, adds another wrinkle to this

552 interpretation. The few eutherocephalians known from the Pristerognathus AZ belong to well-

553 known groups (the whaitsioid family Hofmeyriidae and baurioid family Ictidosuchidae) deeply

554 nested within Eutherocephalia and appear in the record seemingly without precedent. In

555 Kotelnich, however, there is a combination of taxa at the base of Eutherocephalia (Gorynychus,

556 possibly Perplexisaurus) and potential early representatives of known eutherocephalian families

557 (e.g., Viatkosuchus). This indicates substantial therocephalian diversification occurring in

558 Laurasia at the time, and suggest that eutherocephalians originated outside of the Karoo and

559 only later migrated to the basin.

560

561 CONCLUSIONS

562 Based on a complete skull and partial skeleton and two additional, fragmentary specimens, a

563 new therocephalian taxon, Gorynychus masyutinae, is described from the (probably) earliest

564 late Permian Kotelnich locality of Russia. Gorynychus is the largest known predatory tetrapod in

565 the Kotelnich assemblage, and demonstrates that therocephalians acted as top predators in

566 Russian as well as South African assemblages during the transition between typical middle and

567 late Permian terrestrial communities. Although falling outside of Eutherocephalia, Gorynychus is 
568 more closely related to eutherocephalians than to the large-bodied therocephalian predators of

569 southern Africa (and possibly earlier Permian assemblages in Russia, if Porosteognathus from

570 the middle Permian Isheevo fauna truly is a scylacosaurid). The Kotelnich therocephalian fauna

571 shows greater diversity of eutherocephalians than probable coeval faunas in South Africa, and

572 suggests that initial diversification in this clade probably was not occurring in the Karoo Basin.

573

574 ACKNOWLEDGEMENTS

575 We thank director A. Toporov, curator T. Berestova, and the other staff members at the Vyatka

576 Paleontological Museum for all of their help. We thank Fernando Abdala and Jun Liu for their

577 helpful reviews of the original manuscript.

578

579 REFERENCES

580 Abdala F, Rubidge BS, van den Heever JA. 2008. The oldest therocephalians (Therapsida,

581 Eutheriodontia) and the early diversification of Therapsida. Palaeontology 51:1011-1024.

582

583 Abdala F, Kammerer CF, Day MO, Jirah S, Rubidge BS. 2014. Adult morphology of the

584 therocephalian Simorhinella baini from the middle Permian of South Africa and the taxonomy,

585 paleobiogeography, and temporal distribution of the Lycosuchidae. Journal of Paleontology

586 88:1139-1153.

587

588 Benson RBJ. 2012. Interrelationships of basal synapsids: cranial and postcranial morphological 589 parititons suggest different topologies. Journal of Systematic Palaeontology 10:601-624.

591 Benton MJ, Newell AJ, Khlyupin AY, Shumov IS, Price GD, Kurkin AA. 2012. Preservation

592 of exceptional vertebrate assemblages in Middle Permian fluviolacustrine mudstones of 
593 Kotel'nich, Russia: stratigraphy, sedimentology, and taphonomy. Palaeogeography,

594 Palaeoclimatology, Palaeoecology 319-320:58-83.

595

596 Boonstra LD. 1953. A new scaloposaurian genus. Annals and Magazine of Natural History $12^{\text {th }}$

597 Series 6:602-605.

598

599 Boonstra LD. 1969. The fauna of the Tapinocephalus Zone (Beaufort beds of the Karoo).

600 Annals of the South African Museum 56:1-73.

601

602 Botha-Brink J, Modesto SP. 2011. A new skeleton of the therocephalian synapsid

603 Olivierosuchus parringtoni from the Lower Triassic South African Karoo Basin. Palaeontology

$604 \quad 54: 591-606$.

605

606

Broom R. 1903. On the classification of the theriodonts and their allies. Report of the South

607 African Association for the Advancement of Science 1:286-294.

608

609

Broom R. 1905. On the use of the term Anomodontia. Records of the Albany Museum 1:266-

610 269.

611

612 Coffa AA. 1999. Sedimentology, stratigraphy and correlation of the continental red bed

613 sequence at the Kotel'nich Late Permian fossil tetrapod localities, Russia. In: Proceedings of

614 International Symposium "Upper Permian Stratotypes of the Volga Region". Geos: Moscow, 77-

61586.

616

617 Day MO, Ramezani J, Bowring SA, Sadler PM, Erwin DH, Abdala F, Rubidge BS. 2015.

618 When and how did the terrestrial mid-Permian mass extinction occur? Evidence from the 
619 tetrapod record of the Karoo Basin, South Africa. Proceedings of the Royal Society B

$620 \quad 282: 20150834$ DOI 10.1098/rspb.2015.0834.

621

622 Efremov IA, Vjuschkov BP. 1955. [Catalog of localities of Permian and Triassic terrestrial 623 vertebrates in the territories of the USSR]. Trudy Paleontologicheskiy Instituta 46:1-184. [In

624 Russian]

625

626 Fourie H. 2013. The postcranial description of Ictidosuchoides (Therapsida: Therocephalia:

627 Baurioidea). Annals of the Ditsong National Museum of Natural History 3:1-10.

628

629 Fourie H, Rubidge BS. 2009. The postcranial skeleton of the basal therocephalian

630 Glanosuchus macrops (Scylacosauridae) and comparisons of morphological and phylogenetic

631 trends amongst the Theriodontia. Palaeontologia africana 44:27-39.

632

633 Hartmann-Weinberg AP. 1937. Pareiasauriden als Leitfossilien. Problemy Paleontologii

634 2/3:649-712.

635

636 Huttenlocker AK. 2009. An investigation into the cladistic relationships and monophyly of

637 therocephalian therapsids. Zoological Journal of the Linnean Society 157:865-891.

638

639 Huttenlocker AK. 2014. Body size reductions in nonmammalian eutheriodont therapsids

640 (Synapsida) during the end-Permian mass extinction. PLoS ONE 9(2):e87553 DOI

$641 \quad 10.1371 /$ journal.pone.0087553.

642 
643 Huttenlocker AK, Botha-Brink J. 2013. Body size and growth patterns in the therocephalian

644 Moschorhinus kitchingi (Therapsida: Eutheriodontia) before and after the end-Permian

645 extinction in South Africa. Paleobiology 39:253-277.

646

647 Huttenlocker AK, Sidor CA. 2016. The first karenitid (Therapsida, Therocephalia) from the

648 upper Permian of Gondwana and the biogeography of Permo-Triassic therocephalians. Journal

649 of Vertebrate Paleontology 36:4 DOI 10.1080/02724634.2016.1111897.

650

651 Huttenlocker AK, Smith RMS. 2017. New whaitsioids (Therapsida: Therocephalia) from the

652 Teekloof Formation of South Africa and therocephalian diversity during the end-Guadalupian

653 extinction. PeerJ 5:e3868 DOI 10.7717/peerj.3868.

654

655 Ivakhnenko MF. 2003. Eotherapsids from the East European placket. Paleontological Journal

$656 \quad 37:$ S339-2465.

657

658 Ivakhnenko MF. 2008. Cranial morphology and evolution of Permian Dinomorpha

659 (Eotherapsida) of Eastern Europe. Paleontological Journal 42:859-995.

660

661 Ivakhnenko MF. 2011. Permian and Triassic therocephals (Eutherapsida) of Eastern Europe.

662 Paleontological Journal 45:981-1144.

663

664 Jablonski D. 2002. Survival without recovery after mass extinctions. Proceedings of the

665 National Academy of Sciences of the United States of America 99:8139-8144 DOI

$666 \quad 10.1073 /$ pnas.102163299

667 
668 Jenkins FA, Jr. 1971. The postcranial skeleton of African cynodonts. Peabody Museum Bulletin $66936: 1-216$.

670

671 Kammerer CF. 2011. Systematics of the Anteosauria (Therapsida: Dinocephalia). Journal of 672 Systematic Palaeontology 9:261-304.

673

674 Kammerer CF. 2014. A redescription of Eriphostoma microdon Broom, 1911 (Therapsida, 675 Gorgonopsia) from the Tapinocephalus Assemblage Zone of South Africa and a review of 676 Middle Permian gorgonopsians. In: Kammerer CF, Angielczyk KD, Fröbisch J, eds. Early 677 Evolutionary History of the Synapsida. Dordrecht: Springer, 171-184, 337 pp. DOI 10.1007/978678 94-007-6841-3_11.

679

680 Kammerer CF. 2015. Cranial osteology of Arctognathus curvimola, a short-snouted 681 gorgonopsian from the Late Permian of South Africa. Papers in Paleontology 1:41-58. 682

683 Kammerer CF, Smith RMH, Day MO, Rubidge BS. 2015. New information on the morphology 684 and stratigraphic range of the mid-Permian gorgonopsian Eriphostoma microdon Broom, 1911. 685 Papers in Palaeontology 1:201-221. 686

687 Kashtanov SG. 1934. [On the discovery of Permian reptiles on the River Vyatka, near the town 688 of Kotelnich]. Priroda 1934:74-75. [In Russian]

690 Kemp TS. 1986. The skeleton of a baurioid therocephalian from the Lower Triassic 691 (Lystrosaurus Zone) of South Africa. Journal of Vertebrate Paleontology 6:215-232. 692 
693 Kurkin, AA. 2011. Permian anomodonts: paleobiogeography and distribution of the group.

694 Paleontological Journal 45:432-444.

695

696 Li J. 2001. The most primitive lower tetrapod fauna in China. Science in China (Series D)

$697 \quad 44: 47-51$.

698

699 Liu J, Abdala F. 2017. The tetrapod fauna of the upper Permian Naobaogou Formation of

700 China: 1. Shiguaignathus wangi gen. et sp. nov., the first akidnognathid therocephalian from

701 China. PeerJ 5:e4150 DOI: 10.7717/peerj.4150.

702

703 Mendrez CH. 1975. Principales variations du palais chez les thérocéphales sud-africains

704 (Pristerosauria et Scaloposauria) au cours du Permien supérieur et du Trias inférieur.

705 Problémes Actuels de Paléontologie-Évolution des Vertébrés. Colloques internationaux du

706 Centre national de la recherche scientifique 218:379-408.

707

708 Osborn HF. 1903. On the primary division of the Reptilia into two sub-classes, Synapsida and

709 Diapsida. Science 17:275-276.

710

711 Sigogneau-Russell D, Sun A-L. 1981. A brief review of Chinese synapsids. Geobios 14:275712279.

713

714 Smith RMH, Rubidge BS, van der Walt M. 2012. Therapsid biodiversity patterns and

715 environments of the Karoo Basin, South Africa. In: Chinsamy A, ed. Forerunners of mammals:

716 radiation, histology, biology. Bloomington and Indianapolis: Indiana University Press, 223-246, $717330 \mathrm{pp}$. 
719 Swofford DL. 2002. PAUP*. Phylogenetic analysis using parsimony (*and other methods).

720 Version 4. Sinauer Associates, Sunderland, Massachusetts.

721

722 Tatarinov LP. 1995a. Viatkosuchus sumini, a new Late Permian therocephalian from the Kirov

723 Region. Paleontological Journal 29:111-128.

724

725 Tatarinov LP. 1995b. A new ictidosuchid Karenites ornamentatus (Theriodontia) from the

726 Upper Permian of the Kotel'nich Locality in the Kirov Region. Russian Journal of Herpetology

$727 \quad 2: 18-33$.

728

729 Tatarinov LP. 1997. A new scaloposaur (Reptilia, Theriodontia) with an unusual sensory

730 system, from the Upper Permian of the Kirov Region. Paleontological Journal 31:655-661.

731

732 Tatarinov LP. 1999a. New theriodonts (Reptilia) from the Late Permian fauna of the Kotelnich

733 Locality, Kirov Region. Paleontological Journal 33:550-556.

734

735 Tatarinov LP. 1999b. The first scaloposaurid (Reptilia, Theriodontia) from Russia (Upper

736 Permian, Kirov Region). Paleontological Journal 33:278-288.

737

738 Tatarinov LP. 2000. New material of scaloposaurians (Reptilia, Theriodontia) from the Upper

739 Permian of the Kotelnich Locality, Kirov Region. Paleontological Journal 34:S187-S202.

740

741 Tsuji LA. 2013. Anatomy, cranial ontogeny and phylogenetic relationships of the pareiasaur

742 Deltavjatia rossicus from the Late Permian of central Russia. Earth and Environmental Science

743 Transactions of the Royal Society of Edinburgh 104:81-122. 
745 Van den Heever JA. 1980. On the validity of the therocephalian family Lycosuchidae (Reptilia:

746 Therapsida). South African Journal of Science 81:111-125.

747

748 Van den Heever JA. 1987. The comparative and functional cranial morphology of the early

749 Therocephalia (Amniota: Therapsida). Unpublished PhD Thesis, University of Stellenbosch, 659

750 pp.

751

752 Van den Heever JA. 1994. The cranial anatomy of the early Therocephalia (Amniota:

753 Therapsida). Universiteit van Stellenbosch Annale 1994:1-59.

754

755 Vjuschkov BP. 1955. [Theriodonts of the Soviet Union]. Trudy Paleontologicheskogo Instituta,

756 Akademiya Nauk SSSR 49:128-175. [in Russian] 
757

758

759

760

761

762

763

764

765

766

767

768

769

770

771

772

773

774

775

776

777

778

779

780

781

782

FIGURE CAPTIONS

Figure 1. Holotype of Gorynychus masyutinae. The two blocks (KPM 346 and 347) making up the majority of the holotype shown in articulation. Holotype also includes two incisor teeth (KPM 348 and 349) disarticulated from the skull but found in association (see Figs. 2C and 10D). Scale bar equals $5 \mathrm{~cm}$. Photograph by Christian F. Kammerer. [planned for page width]

Figure 2. Anterior snout and dentition of Gorynychus masyutinae. (A) Photograph and (B) interpretive drawing of the skull (KPM 346) in anterior view. (C) Disarticulated incisor (KPM 348) associated with skull in presumed anterior or anterolateral view. Abbreviations: apc, anterior premaxillary channel; mx, maxilla; na, nasal; nr, naris; pmx, premaxilla; smx, septomaxilla. Gray coloration indicates matrix. Scale bars equal $1 \mathrm{~cm}$. Photographs and drawing by Christian F. Kammerer. [planned for page width]

Figure 3. Holotype of Gorynychus masyutinae in dorsal view. (A) Photograph and (B) interpretive drawing of skull (KPM 346). Abbreviations: d, dentary; fr, frontal; j, jugal; la, lacrimal; mx, maxilla; na, nasal; pmx, premaxilla; po, postorbital; prf, prefrontal; qpt, quadrate ramus of pterygoid; smx, septomaxilla; sq, squamosal. Gray coloration indicates matrix, patterning indicates eroded or broken bone surface. Scale bar equals $1 \mathrm{~cm}$. Photograph and drawing by Christian F. Kammerer. [planned for page width]

Figure 4. Holotype of Gorynychus masyutinae in right lateral view. (A) Photograph and (B) interpretive drawing of skull (KPM 346). Abbreviations: ar, articular; C, upper canine; co, coronoid process of dentary; d, dentary; fr, frontal; i, lower incisor; j, jugal; la, lacrimal; mx, maxilla; na, nasal; pmx, premaxilla; prf, prefrontal; PC, upper postcanine; po, postorbital; q-qj, quadrate-quadratojugal complex; rla, reflected lamina of angular; sa, surangular; smx, 
783

784

785

786

787

788

789

790

791

792

793

794

795

796

797

798

799

800

801

802

803

804

805

806

807 [planned for page width] for page width]

septomaxilla; sq, squamosal; ss, squamosal sulcus. Gray coloration indicates matrix, patterning indicates eroded or broken bone surface. Scale bar equals $1 \mathrm{~cm}$. Photograph and drawing by Christian F. Kammerer. [planned for page width]

Figure 5. Holotype of Gorynychus masyutinae in left lateral view. (A) Photograph and (B) interpretive drawing of skull (KPM 346). Abbreviations: C, upper canine; co, coronoid process of dentary; d, dentary; ept, epipterygoid; fr, frontal; j, jugal; la, lacrimal; mx, maxilla; na, nasal; os, orbitosphenoid; pa, parietal; pmx, premaxilla; prf, prefrontal; PC, upper postcanine; po, postorbital; qpt, quadrate ramus of pterygoid; rla, reflected lamina of angular; sa, surangular; smx, septomaxilla. Gray coloration indicates matrix, patterning indicates eroded or broken bone surface. Scale bar equals $1 \mathrm{~cm}$. Photograph and drawing by Christian F. Kammerer. [planned

Figure 6. Postcanine morphology of Gorynychus masyutinae. Left PC1-3 in lateral view. $\mathrm{PC} 2$ is in the process of erupting. Scale bar equals $1 \mathrm{~cm}$. Photograph by Christian F. Kammerer. [planned for column width]

Figure 7. Holotype of Gorynychus masyutinae in ventral view. (A) Photograph and (B) interpretive drawing of skull (KPM 346). Abbreviations: an, angular; ar, articular; bt, basal tuber; C, upper canine; d, dentary; j, jugal; mx, maxilla; oc, occipital condyle; pl, palatine; pra, prearticular; ps, parabasisphenoid; pt, palatal portion of pterygoid; q, quadrate; qpt, quadrate ramus of pterygoid; ri, rib; rla, reflected lamina of angular; sf, suborbital fenestra; sp, splenial; sq, squamosal; st, stapes; tpt, transverse process of pterygoid; v, vomer. Gray coloration indicates matrix. Scale bar equals $1 \mathrm{~cm}$. Photograph and drawing by Christian F. Kammerer.

808 
809 Figure 8. Cervical vertebrae of Gorynychus masyutinae (KPM 346-347). (A) Photograph

810 and (B) interpretive drawing. Abbreviations: as, axial neural spine; c, cervical vertebra; cr,

811 cervical rib; ic, intercentrum; ns, neural spine; poz, postzygapophysis; prz, prezygapophysis;

812 sf?, possible skull fragment; tp, transverse process. Gray coloration indicates matrix. Scale bar

813 equals $5 \mathrm{~cm}$. Photograph and drawing by Christian F. Kammerer. [planned for page width]

814

815 Figure 9. Postcranial elements of Gorynychus masyutinae (KPM 347). (A) Photograph and

816 (B) interpretive drawing. Abbreviations: ?, unknown bone; c, cervical vertebra; cl?, possible

817 clavicle; ri, rib; sc, scapulocoracoid; ve, vertebra. Gray coloration indicates matrix. Scale bar

818 equals $5 \mathrm{~cm}$. Photograph and drawing by Christian F. Kammerer. [planned for page width]

819

820 Figure 10. KPM 291, a block containing disarticulated elements referred to Gorynychus

821 masyutinae. (A) Photograph and (B) interpretive drawing. Abbreviations: ax, axis vertebra; $d$,

822 dentary; i, incisor; po?, postorbital?; r, rib; ve, vertebra. Elements marked with asterisks are

823 shown in greater detail in Figure 10. Scale bar equals $5 \mathrm{~cm}$. Photograph and drawing by

824 Christian F. Kammerer. [planned for page width]

825

826 Figure 11. Disarticulated elements of Gorynychus masyutinae. (A-C) are highlighted

827 elements of KPM 291 (see Fig. 9): (A) Anterior portion of right dentary preserving lower canine;

828 (B) ?dorsal vertebra; and (C) incisor tooth. (D) is another isolated incisor (KPM 448/1). Scale

829 bars equal $1 \mathrm{~cm}$. Photographs by Christian F. Kammerer. [planned for page width]

830

831 Figure 12. Cladogram showing phylogenetic position of Gorynychus masyutinae. Strict

832 consensus of 1260 most parsimonious trees. Numbers at nodes represent bootstrap values,

833 major clades labeled at nodes. Image by Christian F. Kammerer [planned for page width] 


\section{Figure 1}

Holotype of Gorynychus masyutinae.

The two blocks (KPM 346 and 347) making up the majority of the holotype shown in articulation. Holotype also includes two incisor teeth (KPM 348 and 349) disarticulated from the skull but found in association (see Figs. 2C and 10D). Scale bar equals $5 \mathrm{~cm}$. Photograph by Christian F. Kammerer.

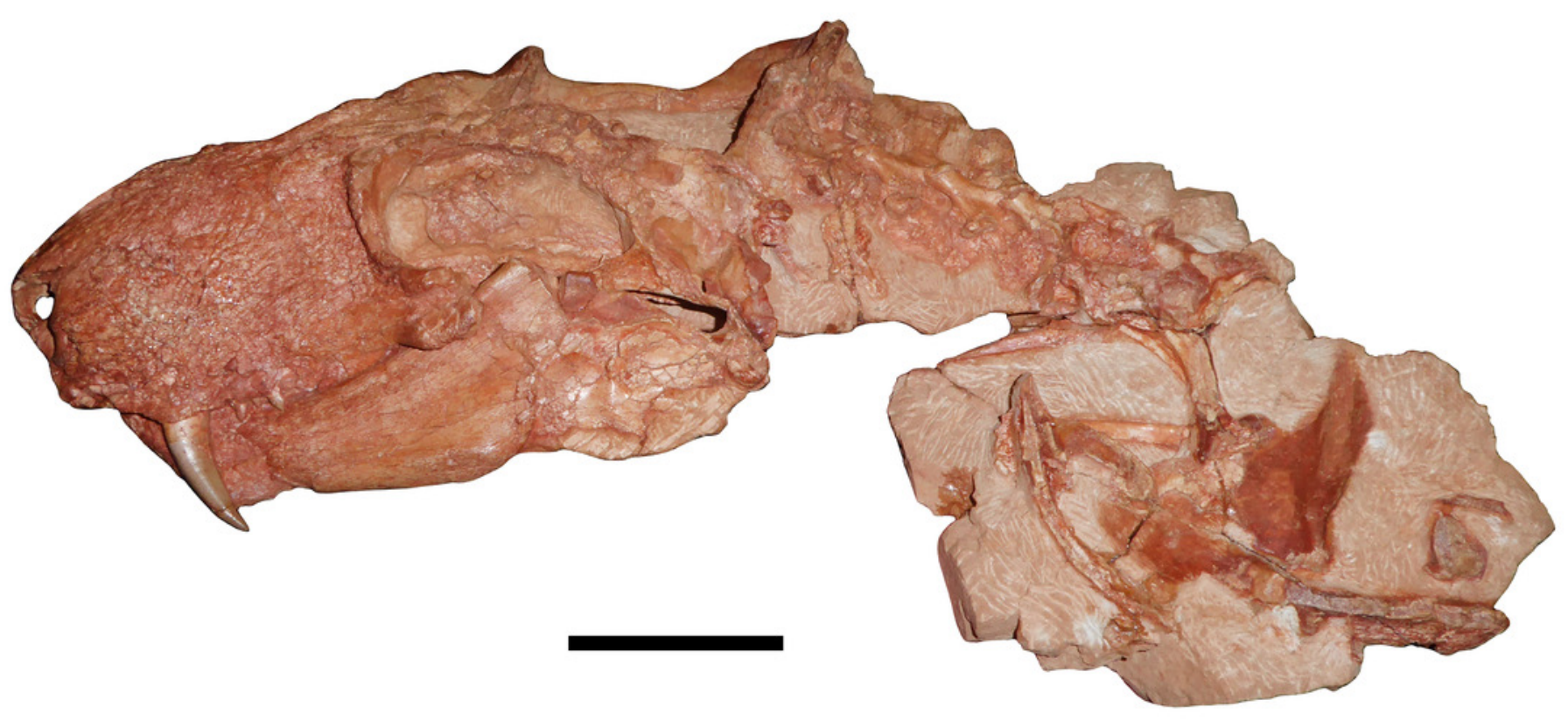


Figure 2

Anterior snout and dentition of Gorynychus masyutinae.

(A) Photograph and (B) interpretive drawing of the skull (KPM 346) in anterior view. (C) Disarticulated incisor (KPM 348) associated with skull in presumed anterior or anterolateral view. Abbreviations: apc, anterior premaxillary channel; $\mathrm{mx}$, maxilla; na, nasal; $\mathrm{nr}$, naris; pmx, premaxilla; smx, septomaxilla. Gray coloration indicates matrix. Scale bars equal $1 \mathrm{~cm}$. Photographs and drawing by Christian F. Kammerer. 

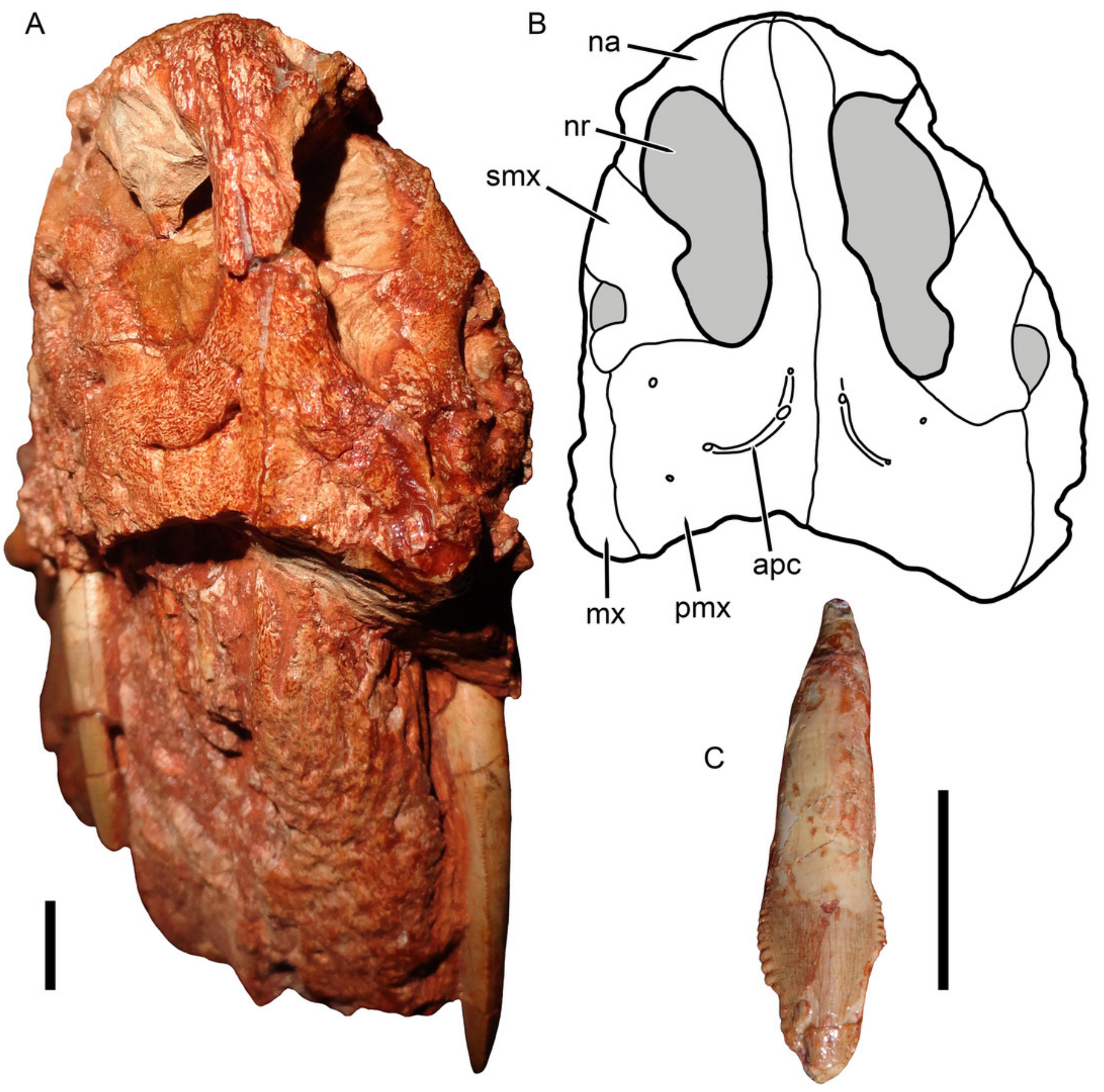
Figure 3

Holotype of Gorynychus masyutinae in dorsal view.

(A) Photograph and (B) interpretive drawing of skull (KPM 346). Abbreviations: d, dentary; fr, frontal; j, jugal; la, lacrimal; mx, maxilla; na, nasal; pmx, premaxilla; po, postorbital; prf, prefrontal; qpt, quadrate ramus of pterygoid; smx, septomaxilla; sq, squamosal. Gray coloration indicates matrix, patterning indicates eroded or broken bone surface. Scale bar equals $1 \mathrm{~cm}$. Photograph and drawing by Christian F. Kammerer.

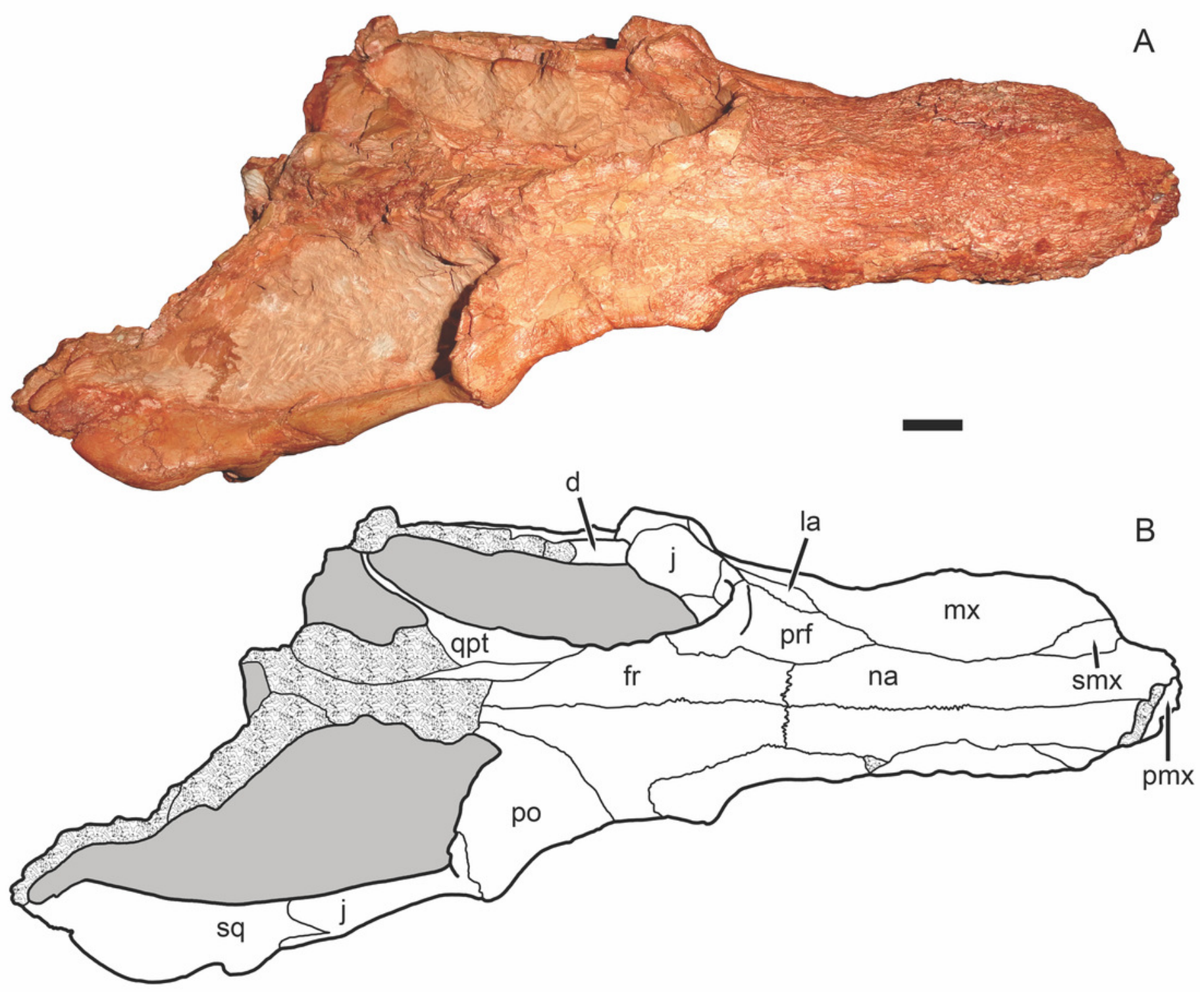




\section{Figure 4}

Holotype of Gorynychus masyutinae in right lateral view.

(A) Photograph and (B) interpretive drawing of skull (KPM 346). Abbreviations: ar, articular; C, upper canine; co, coronoid process of dentary; d, dentary; fr, frontal; i, lower incisor; j, jugal; la, lacrimal; mx, maxilla; na, nasal; pmx, premaxilla; prf, prefrontal; PC, upper postcanine; po, postorbital; q-qj, quadrate-quadratojugal complex; rla, reflected lamina of angular; sa, surangular; smx, septomaxilla; sq, squamosal; ss, squamosal sulcus. Gray coloration indicates matrix, patterning indicates eroded or broken bone surface. Scale bar equals $1 \mathrm{~cm}$. Photograph and drawing by Christian F. Kammerer. 

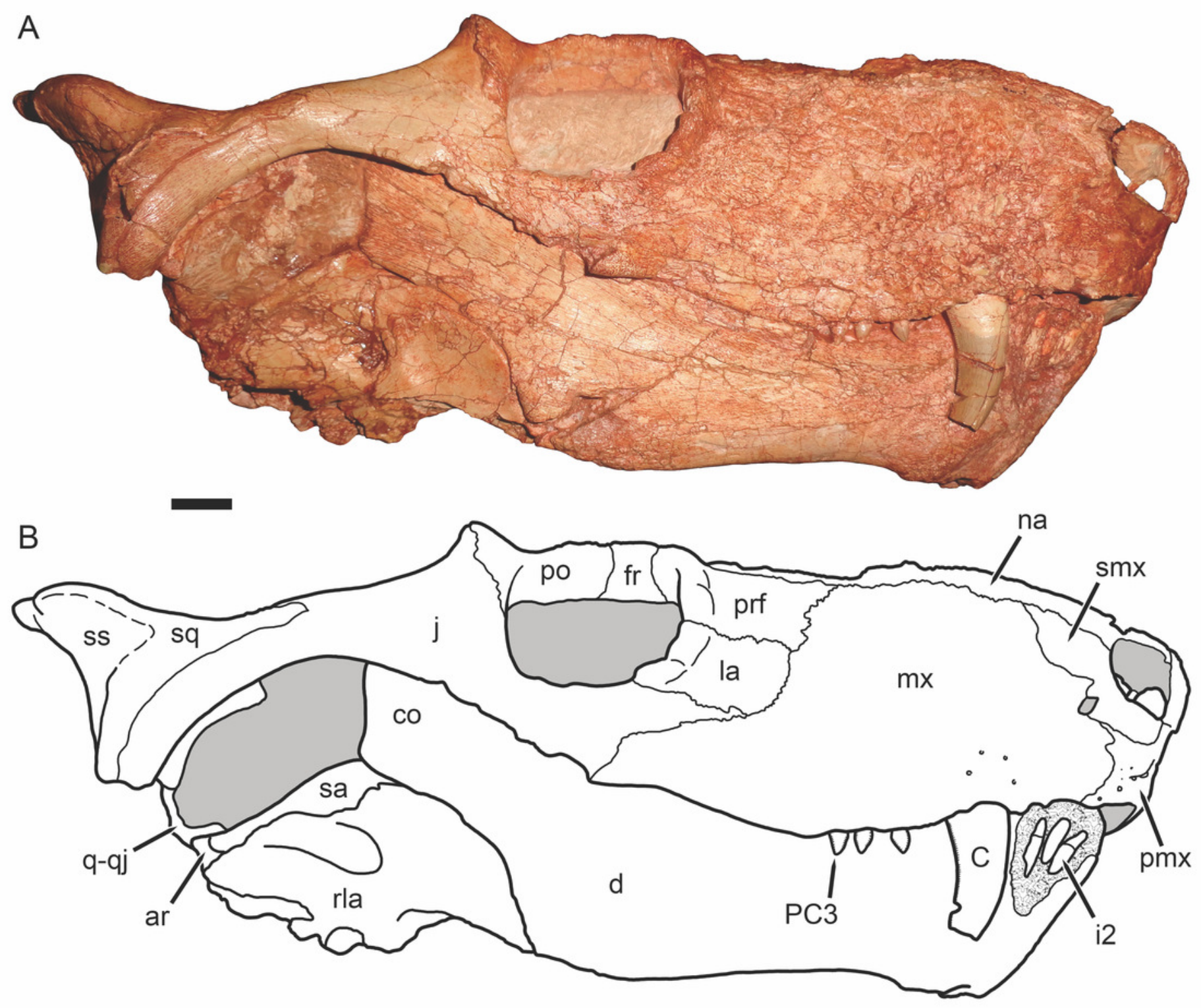


\section{Figure 5}

Holotype of Gorynychus masyutinae in left lateral view.

(A) Photograph and (B) interpretive drawing of skull (KPM 346). Abbreviations: C, upper canine; co, coronoid process of dentary; d, dentary; ept, epipterygoid; fr, frontal; j, jugal; la, lacrimal; mx, maxilla; na, nasal; os, orbitosphenoid; pa, parietal; pmx, premaxilla; prf, prefrontal; PC, upper postcanine; po, postorbital; qpt, quadrate ramus of pterygoid; rla, reflected lamina of angular; sa, surangular; smx, septomaxilla. Gray coloration indicates matrix, patterning indicates eroded or broken bone surface. Scale bar equals $1 \mathrm{~cm}$. Photograph and drawing by Christian F. Kammerer. 


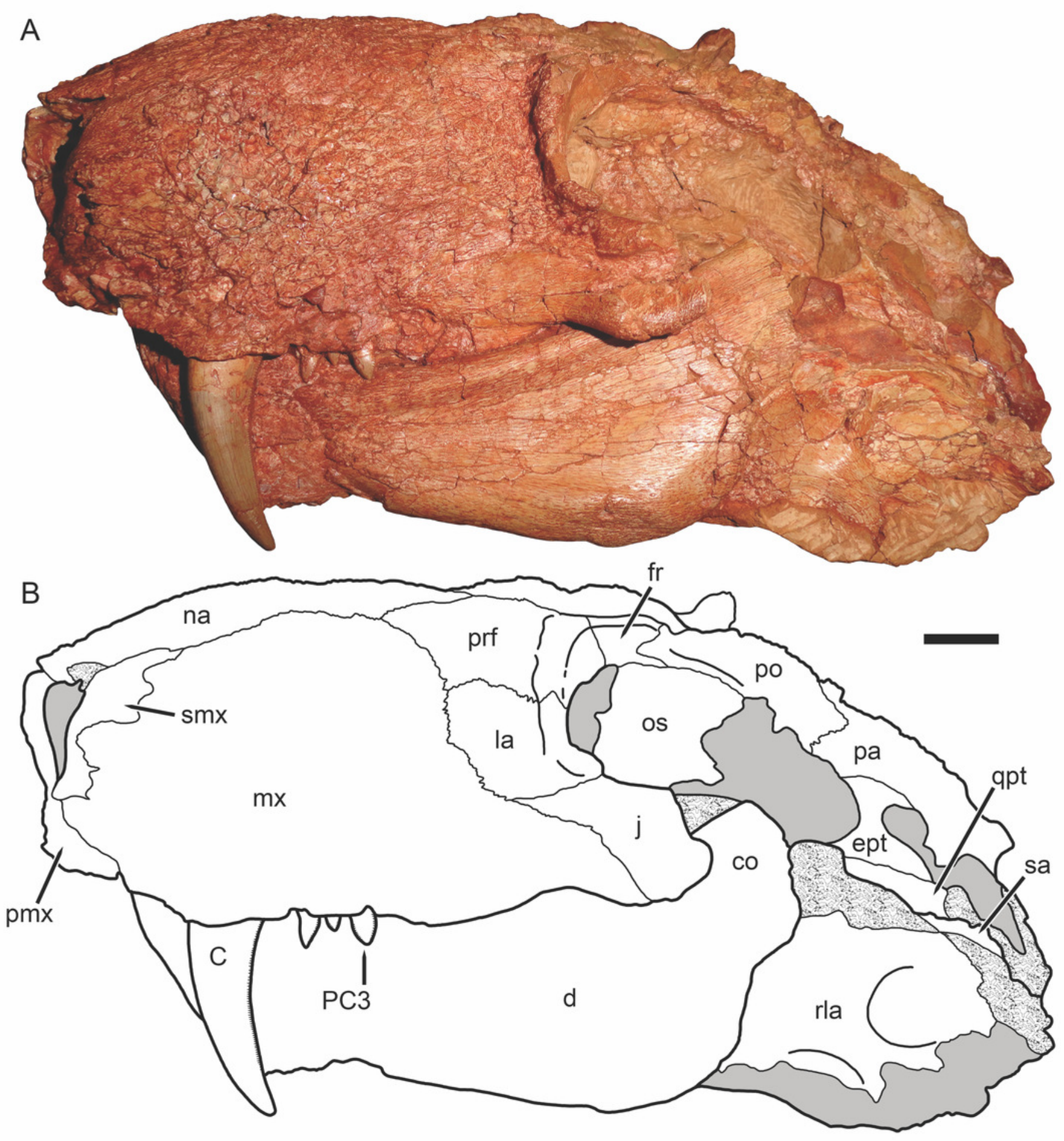




\section{Figure 6}

Postcanine morphology of Gorynychus masyutinae.

Left PC1-3 in lateral view. PC2 is in the process of erupting. Scale bar equals $1 \mathrm{~cm}$.

Photograph by Christian F. Kammerer.

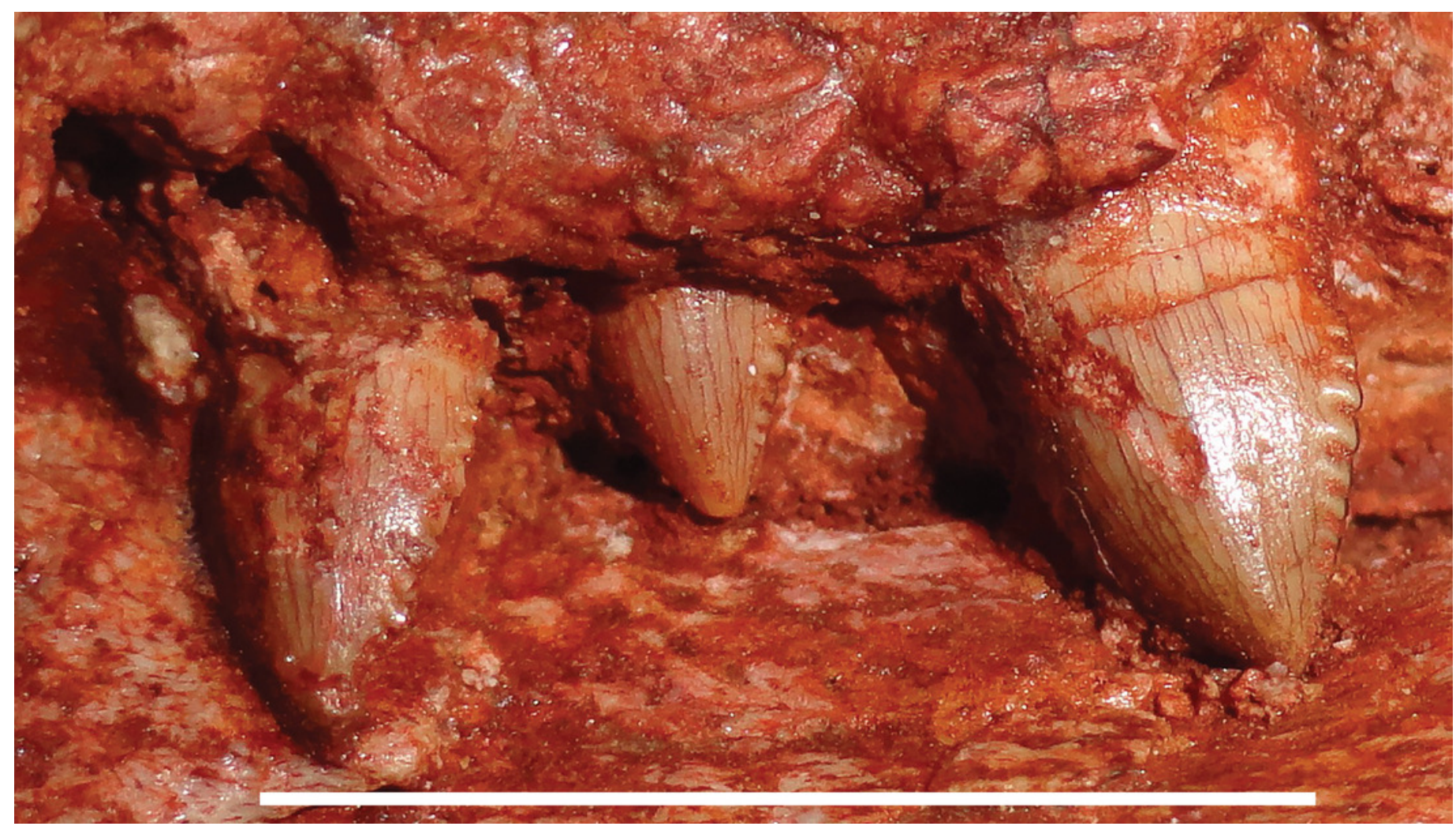




\section{Figure 7}

Holotype of Gorynychus masyutinae in ventral view.

(A) Photograph and (B) interpretive drawing of skull (KPM 346). Abbreviations: an, angular; ar, articular; bt, basal tuber; C, upper canine; d, dentary; j, jugal; mx, maxilla; oc, occipital condyle; pl, palatine; pra, prearticular; ps, parabasisphenoid; pt, palatal portion of pterygoid; q, quadrate; qpt, quadrate ramus of pterygoid; ri, rib; rla, reflected lamina of angular; sf, suborbital fenestra; sp, splenial; sq, squamosal; st, stapes; tpt, transverse process of pterygoid; v, vomer. Gray coloration indicates matrix. Scale bar equals $1 \mathrm{~cm}$. Photograph and drawing by Christian F. Kammerer. 

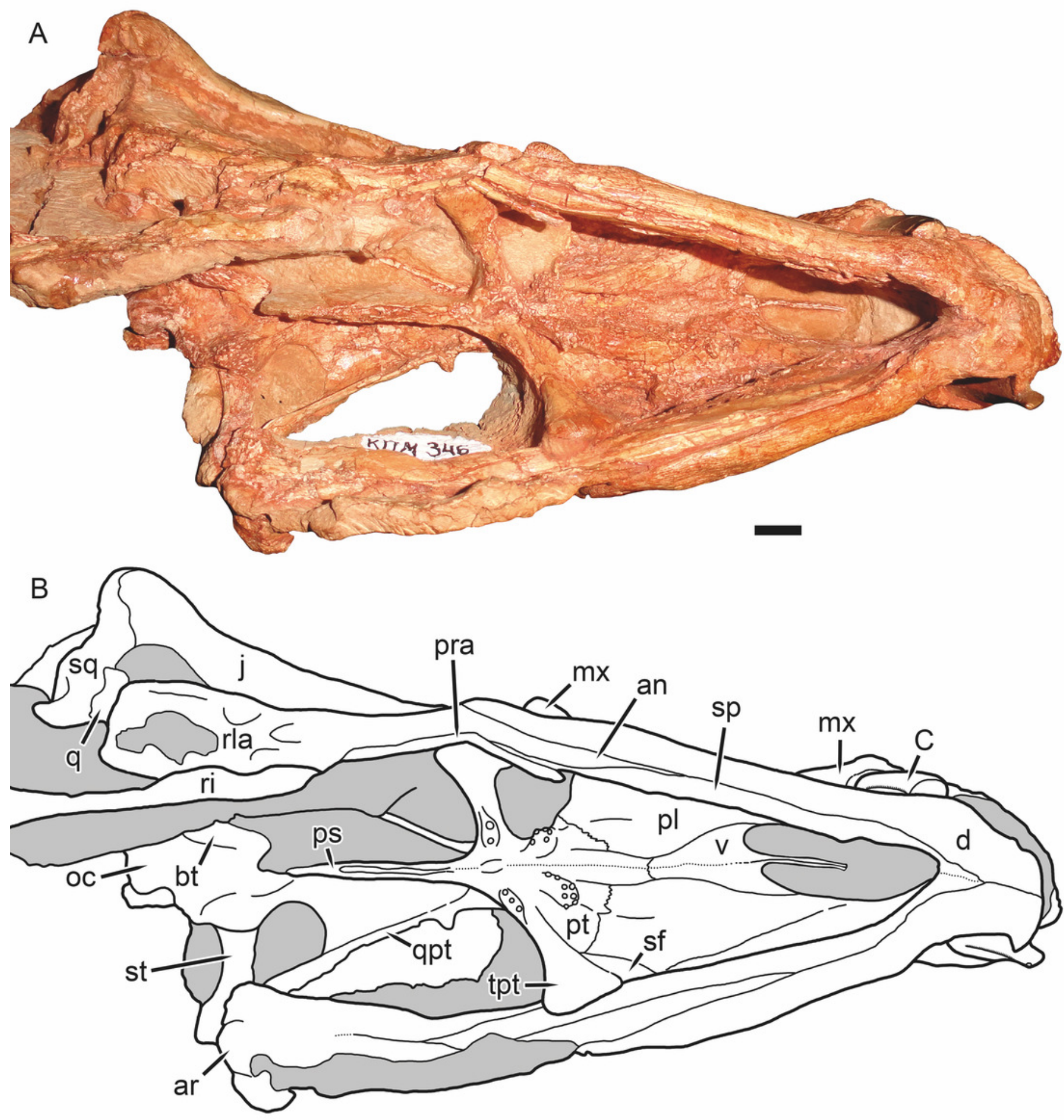
Figure 8

Cervical vertebrae of Gorynychus masyutinae (KPM 346-347).

(A) Photograph and (B) interpretive drawing. Abbreviations: as, axial neural spine; $c$, cervical vertebra; cr, cervical rib; ic, intercentrum; ns, neural spine; poz, postzygapophysis; prz, prezygapophysis; sf?, possible skull fragment; tp, transverse process. Gray coloration indicates matrix. Scale bar equals $5 \mathrm{~cm}$. Photograph and drawing by Christian F. Kammerer.

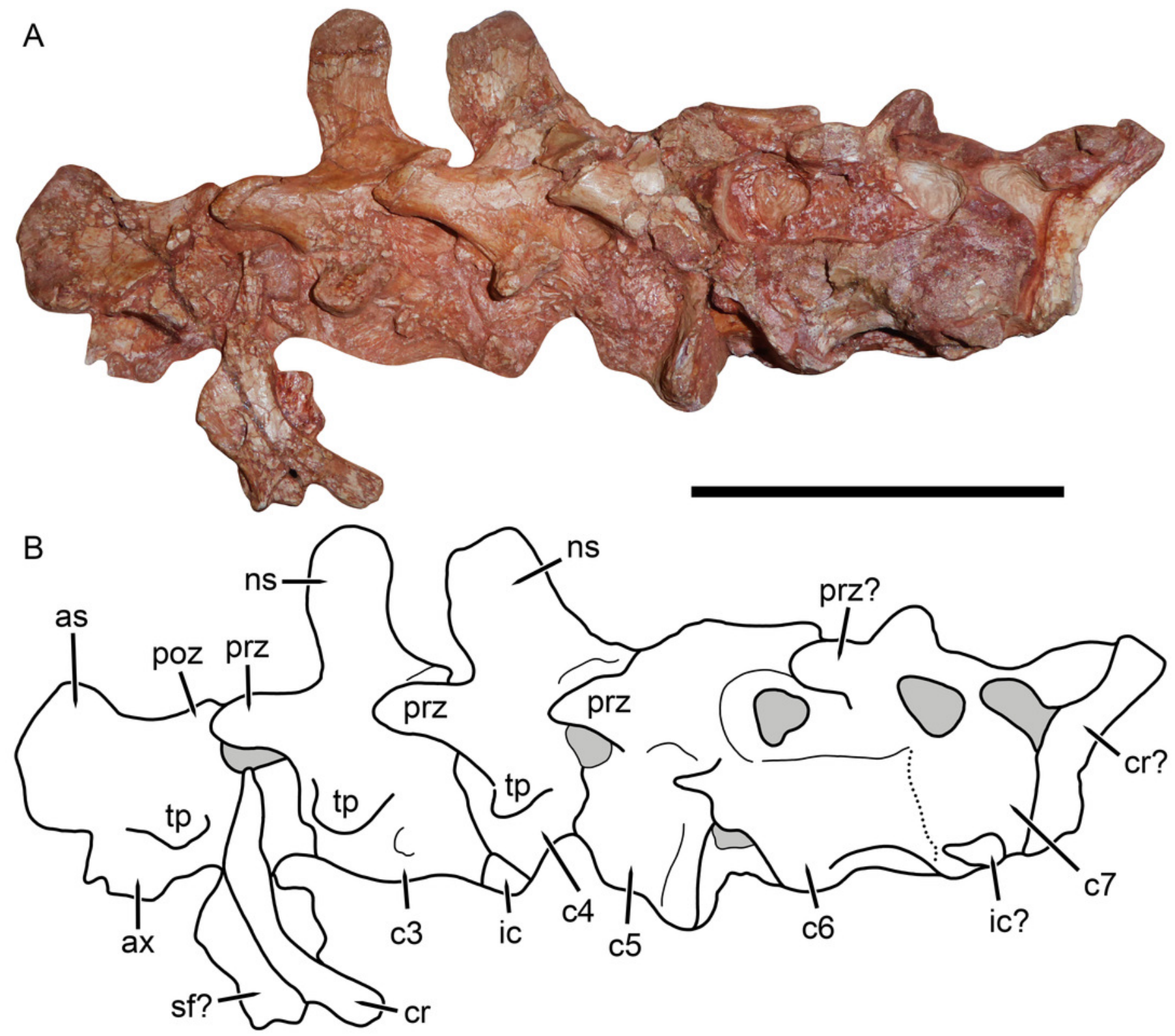


Figure 9

Postcranial elements of Gorynychus masyutinae (KPM 347).

(A) Photograph and (B) interpretive drawing. Abbreviations: ?, unknown bone; c, cervical vertebra; cl?, possible clavicle; ri, rib; sc, scapulocoracoid; ve, vertebra. Gray coloration indicates matrix. Scale bar equals $5 \mathrm{~cm}$. Photograph and drawing by Christian F. Kammerer.
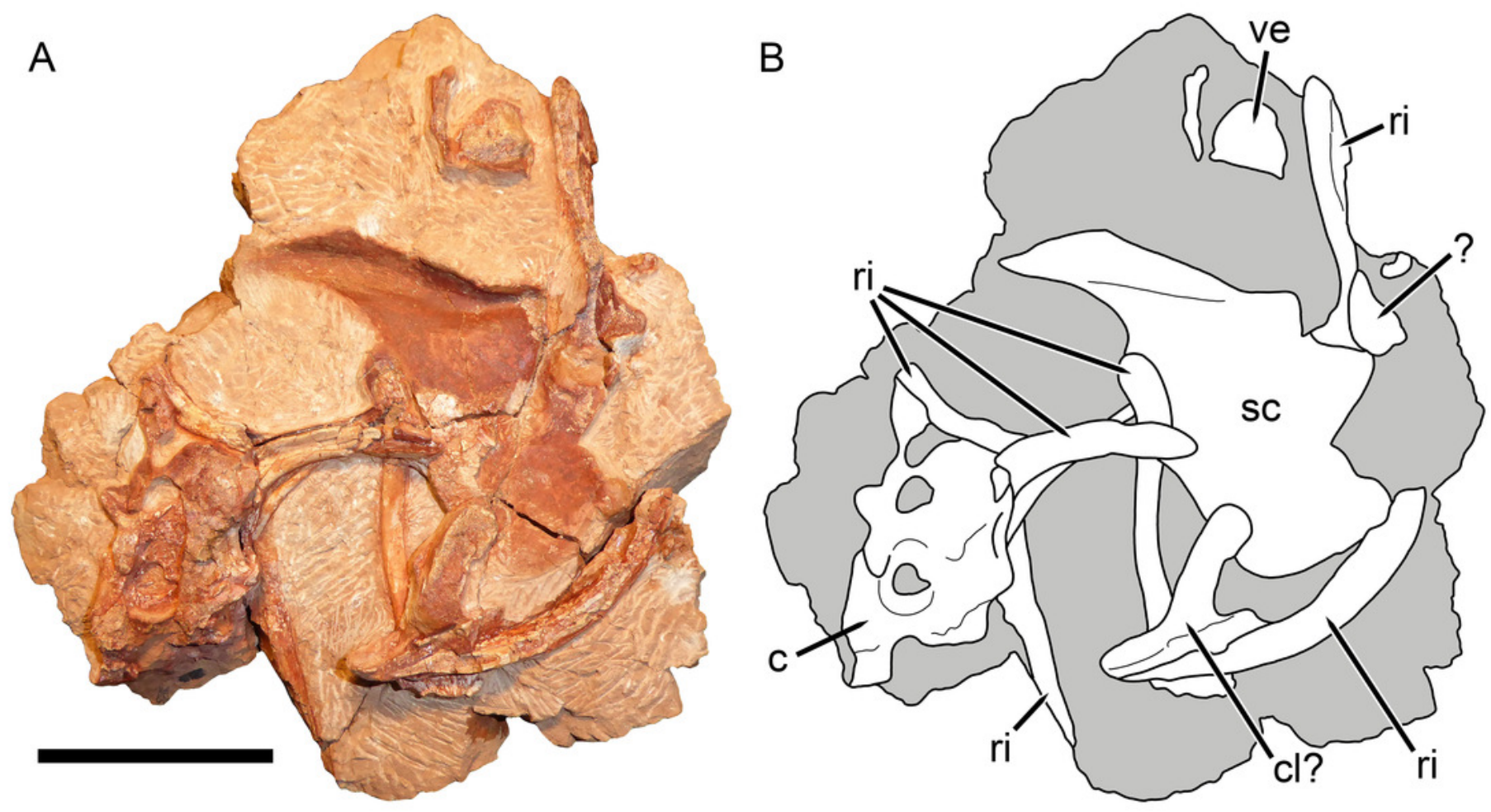


\section{Figure 10}

KPM 291, a block containing disarticulated elements referred to Gorynychus masyutinae gen. et sp. nov.

(A) Photograph and (B) interpretive drawing. Abbreviations: ax, axis vertebra; d, dentary; i, incisor; po?, postorbital?; r, rib; ve, vertebra. Elements marked with asterisks are shown in greater detail in Figure 10. Scale bar equals $5 \mathrm{~cm}$. Photograph and drawing by Christian F. Kammerer. 


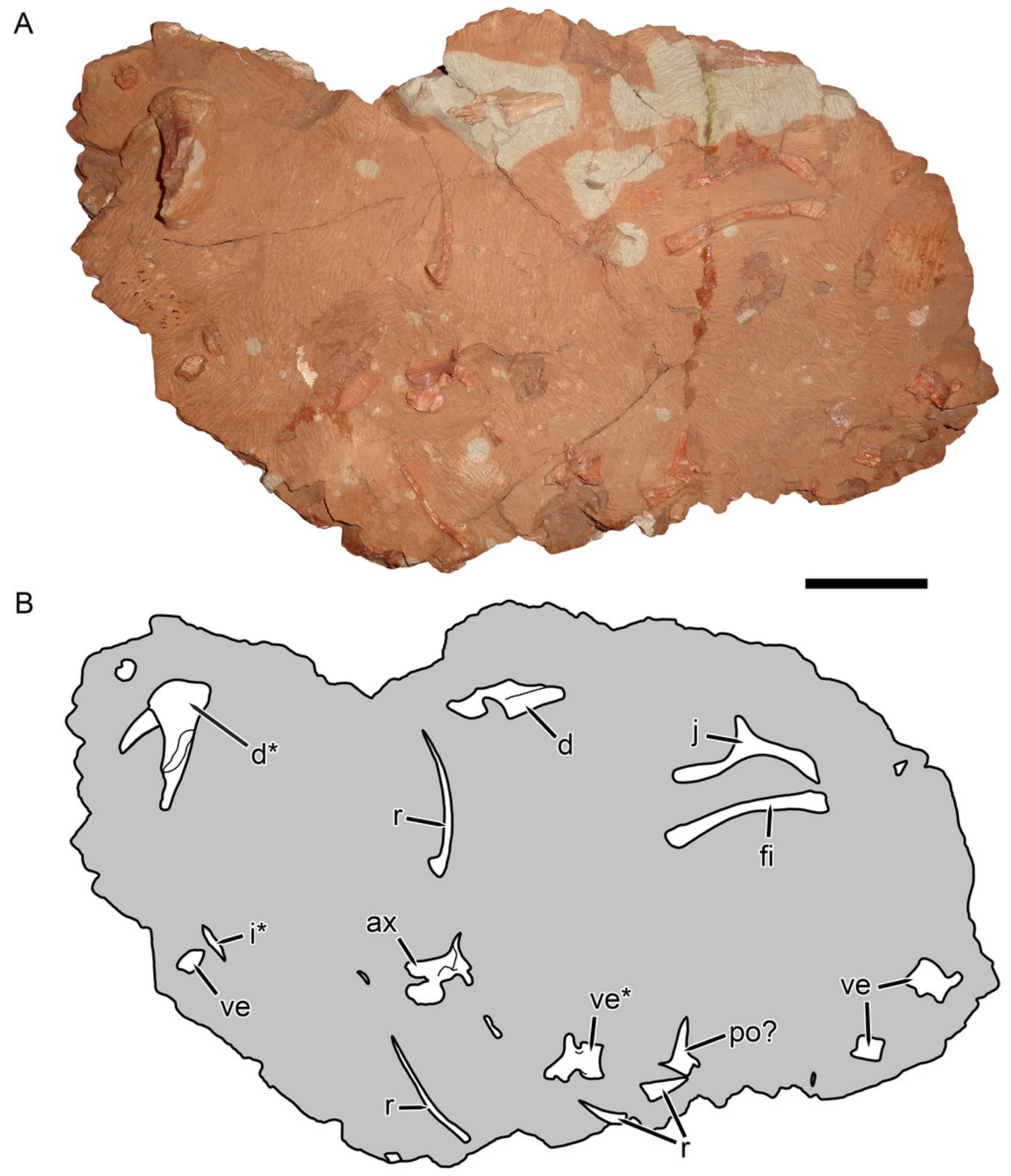


Figure 11

Disarticulated elements of Gorynychus masyutinae.

(A-C) are highlighted elements of KPM 291 (see Fig. 9): (A) Anterior portion of right dentary preserving lower canine; (B) ?dorsal vertebra; and (C) incisor tooth. (D) is another isolated incisor (KPM 448/1). Scale bars equal $1 \mathrm{~cm}$. Photographs by Christian F. Kammerer.

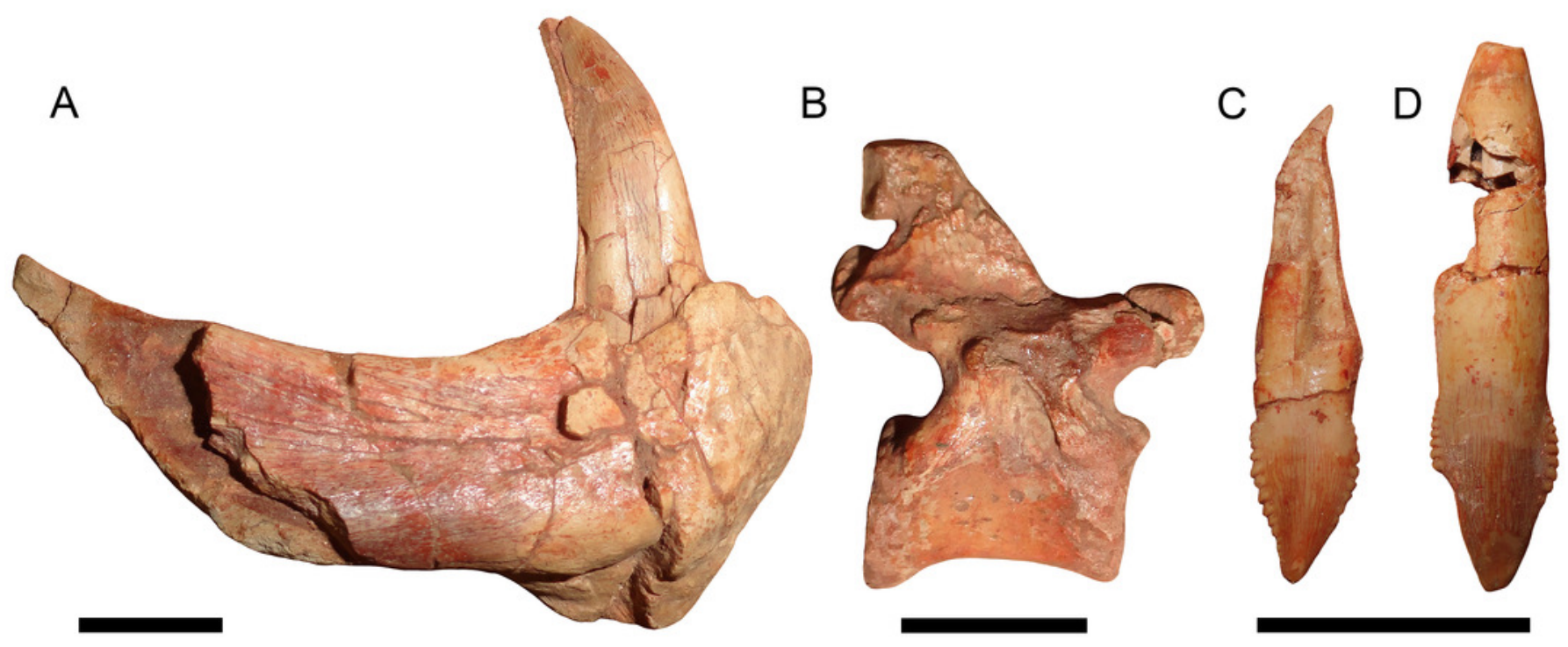




\section{Figure 12}

Cladogram showing phylogenetic position of Gorynychus masyutinae.

Strict consensus of 1260 most parsimonious trees. Numbers at nodes represent bootstrap values, major clades labeled at nodes. Image by Christian F. Kammerer. 


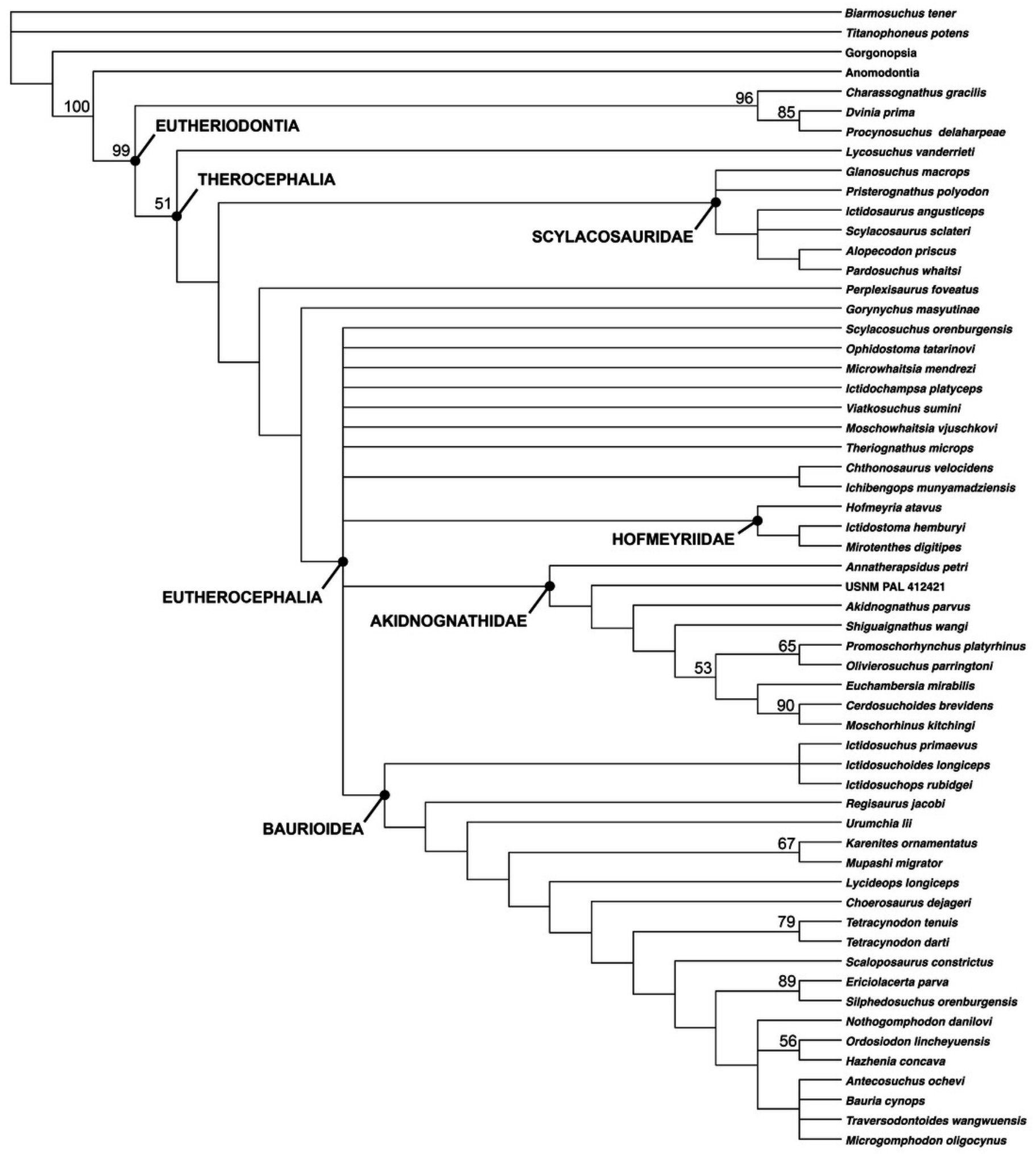

